\title{
Impacts of Intangible Assets on Regional Growth and Unemployment
}

\author{
Christian Dreger ${ }^{1}$ Georg Erber $^{2}$ and \\ Hannah Wesker \\ ${ }^{1}$ Department of Macro Analysis and Forecasting (KON) \\ ${ }^{2}$ Department of Information Society and Competition (IGW), \\ at DIW Berlin, Mohrenstrasse 58, 10117 Berlin, Germany
}

\begin{abstract}
The paper studies the impact of intangible assets on economic growth and unemployment from a regional perspective. The familiar relationship between changes in the unemployment rate and economic growth - known as Okun's law - is taken as a workhorse of the analysis and estimated for the 27 EU-member countries at the NUTS 1 level ${ }^{1}$. The results establish Okun's law as a firm relationship to describe the growth-uemployment nexus. However, the analysis reveals substantial heterogeneities across the regions. In fact, the law is more inline with the regions of the old EU-member states. Similarly in Germany a significant East-Westdivide is observable. In addition there seems to be a separation between Northern and the Southern European regions. Therefore, the model is extended by including spatial effects to identify if there are significant spillovers, and whether they have changed over the integration process. Our findings confirm the hypothesis that spatial dependencies matter for the Okun relationship. The evidence is based on the spatial error and the spatial lag model although the former has a slightly better performance than the latter alternative. Due to the high regional aggregation level direct neighbourhood effects are dominant The importance of spatial effects has risen over time, i.e. the economic development has become more similar in the integration process. For less advanced regions regional economic growth and unemployment do not depend on intangible assets.
\end{abstract}

\footnotetext{
${ }^{1}$ NUTS - Nomenclature des unités territoriales statistiques systematic by the European Union. The NUTS 1 level used distinguish 97 regions (95 of the standard differentiation plus 2 additional ones separating Sweden into three specific regions).
} 


\section{Table of contents}

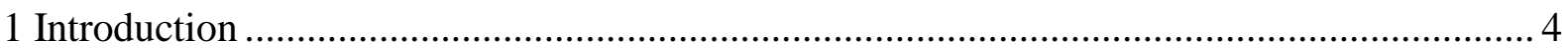

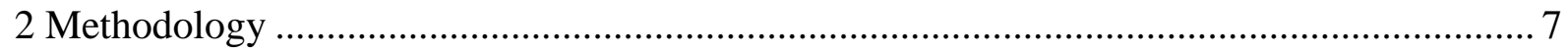

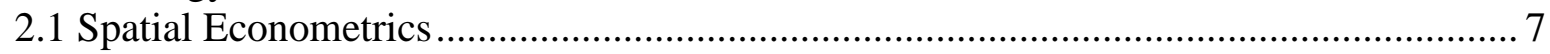

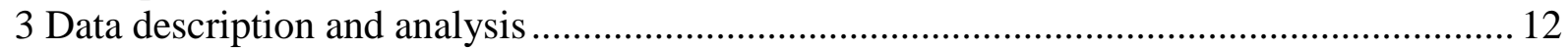

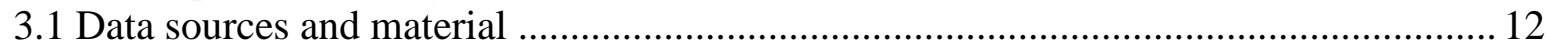

3.2 Empirical analysis of Okun's Law and distribution of GDP growth in Europe ............ 13

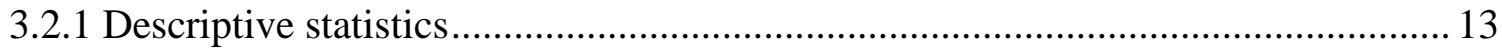

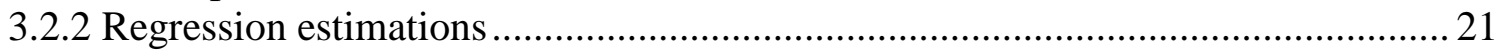

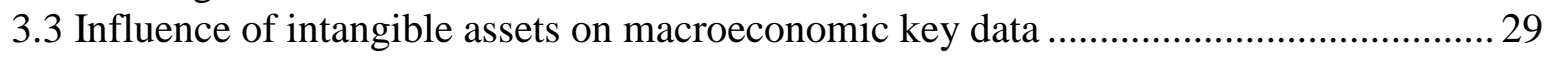

3.3.1 Determinants of the growth rate of the GDP: Intangible assets ............................ 29

3.3.2 Impacts of intangible asstes on the regional unemployment ratios......................... 34

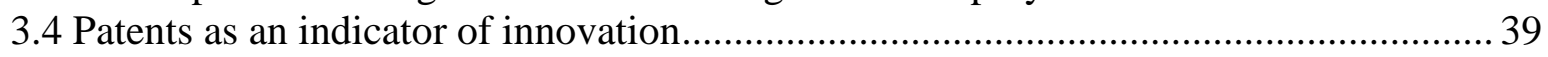

3.4.1 Descriptive statistics concerning the total number and different sectors of patents 39

3.4.2 Determinants of the growth rate of patents ..................................................... 43

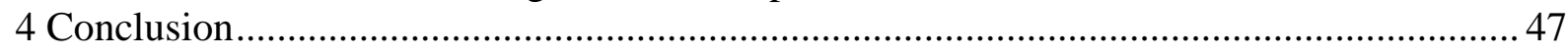

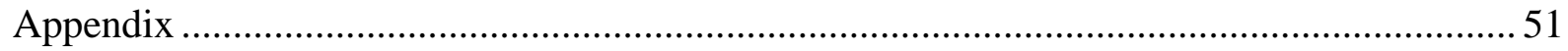

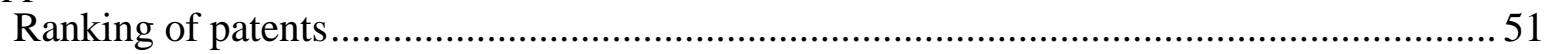

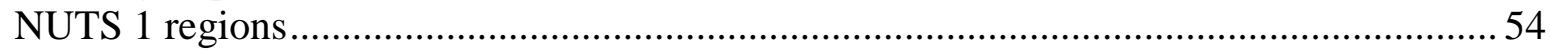

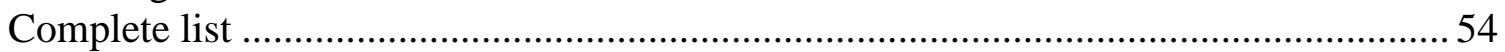

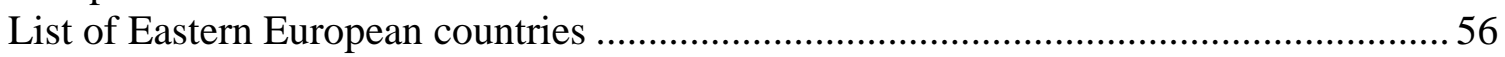

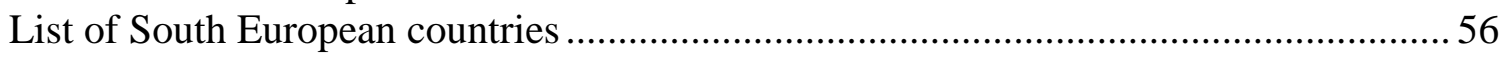




\section{List of figures}

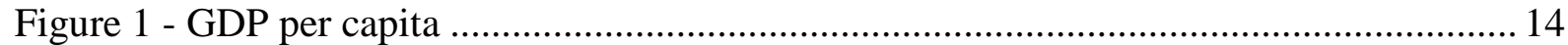

Figure 2 - Histogram of the per capita GDP ……………….............................................. 14

Figure 3 - Boxplot of the per capita GDP for selected countries ............................................ 14

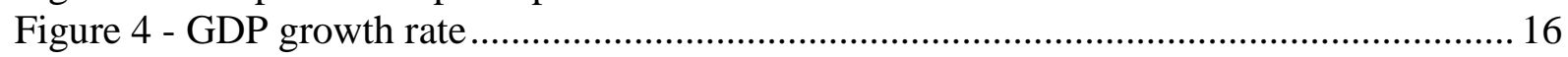

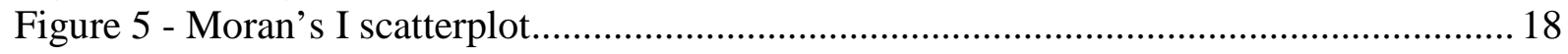

Figure 6- Unemployment ratio …………………………………………………... 20

Figure 7 - Descriptive statistics of the residual series ........................................................ 23

Figure 8 - Residual graph ........................................................................................ 23

Figure 9 - Labour force with a university degree or equivalent relative to the total labour

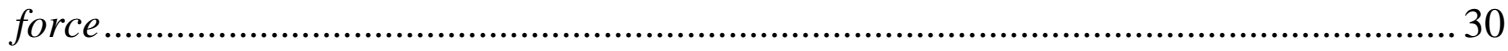

Figure 10 - Expenditure for research and development per person ……………………….....31

Figure 11 - Human resources in science and technology relative to the total labour force ..... 32 Figure 12 - spatial autocorrelation of unemployment rate and change of unemployment rate 36 Figure 13 - Number of registered patents per one million inhabitants...................................... 39

\section{List of tables}

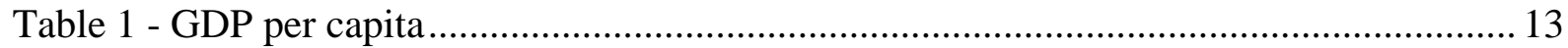

Table 2 - GDP per capita growth rate (year 2004) ……………………………………..... 16

Table 3 - Unemployment ratio (year 2006) ........................................................................ 20

Table 4 - Change in the unemployment ratio .................................................................... 21

Table 5 - Number of patents per one million inhabitants (2002) ………………………........ 39

Table 6 - Number of patents in the hightechnology sector per one million inhabitants (2002)

Table 7 - Research and development expenditure divided by the total number of patents

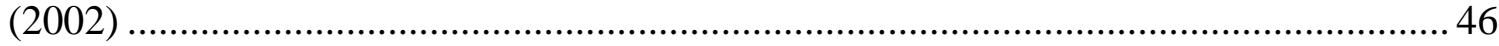

Table 8 - Human resources in science and technology divided by the total number of patents (2002). 


\title{
Impacts of Intangible Assets on Regional Growth and Unemployment
}

\author{
Christian Dreger, Georg Erber and \\ Hannah Wesker \\ preliminary \\ Please do not quote without permission
}

\section{Introduction}

Intangible assets, like education and knowledge embodied in the labor force and accumulated as human capital (see e.g. Becker 1964, 1993, Rosen 1987) are considered to be a key ingredient of intangible capital which have to be considered beside the physical capital (equipment and structures) for which general accounting practices have already been developed over the last decades. Beside the human resources other intangible assets are playing increasingly a key role in a knowledge based economy.

The innovation abilities of an ensemble of workers employed at a company making efficient use of physical resources inside and outside the firm, are nowadays another important determinant of economic growth, this organizational abilities are also called organizational capital as the entity of an enterprise as a social organization. The lack of a proper structure of an organization leads to severe efficiency losses (see e.g. Burt 1992, Brynjolfsson, Hitt, Yang 2002). Furthermore the economic environment summarized by institutions or cultural habits and attitudes forming social relations have been considered an additional factor. The term established to summarize these elements is social capital (see e.g. de Clercq, Dakhli 2005).

In capital markets in particular through mergers and acquisitions the willingness to buy into a company not only for participating by increasing stock prices or dividend payments has 
become known as the market for corporate control (see e.g. von Thadden 1990). The valuation of a company as a highly specific organization which is differentiated by its organizational structure, its human capital and other intangible assets (intellectual property rights like patents, copyrights, brand names or trade secrets like customer and supplier relations) from all others, has become more and more an essential asset which often exceed the valuation of the physical assets included in the traditional balance sheets (see e.g. Enhanced Business Reporting Consortium, EBRC ${ }^{2}$, “Arbeitskreis Wissensbilanz”3).

Beside the micro perspective of proper accounting of intangible assets at the firm level there is as well an increasing awareness that intangible assets have to be included in the macroeconomic analysis as well. As Mankiw, Romer and Weil (1992) or Barro and Sala-iMartin (1995, $20032^{\text {nd }}$ ed.) and others like de la Fuente and Doménech (2006) have shown human capital - an intangible asset - is a central element for explaining differences in growth performance of different economies. They especially point out the importance of measurement errors which tend to bias results of econometric studies when relying on official data. Jones (2005) has recently compared the structure of different human capital based growth theories with strong and weak scale effects to point out their similarities.

Since human capital is only one element of the whole bundle of intangible assets it cannot properly measure the overall impact of intangible assets on the macro level correctly (see e.g. Corrado, Hulten, Sichel 2006, Hill 2003, David 2001). This raises the suspicion that current empirical studies are bias towards human capital and neglecting the impacts of further intangible assets. The European Observatory on Intangible Assets estimated that in Sweden totoal investments in intangible assets tend to exceed those in tangibles, i.e. physical capital. They refer to Swedish estimates that the share of investment flows geared to intangible assets is at 20 percent of GDP. Corrado, Hulten and Sichel claim that in the US that as much as $\$ 800$ billion dollars are still excluded from the official US statistical published data in 2003. Their estimate implies that official statistics exclude an intangible capital stock of about $\$ 3$ trillion dollars (Corrado, Hulten, Sichel 2006). All these different studies point in a direction that current analysis based on the system of national accounts data excluding intangible assets severely underestimate the impact of intangible assets on the economy.

\footnotetext{
${ }^{2}$ EBRC was set up jointly by AICPA (American Institute of Certified Public Accountants) and various companies. See www.ebr360.org

${ }^{3}$ This is a tudy group on knowledge balance sheets promoted by the German Federal Ministry of Economics and Technology. See www.akwissensbilanz.org.
} 
Recently a number of EU financed research projects like IAREG $^{4}$ or Innodrive ${ }^{5}$ as part of the $7^{\text {th }}$ EU-Framework Program are developing concepts and databases which offer a more general accounting framework for intangible assets to be applied in the analysis of the impacts of intangible assets on growth, employment and productivity. Already as part of the EU $6^{\text {th }}$ Framework Program numerous projects addressing this topic were launched. ${ }^{6}$

Intangible assets of growing importance for firms nowadays are intangibles embodied in property rights like legal intangibles (copyrights, patents or trademarks). These legal intangibles protect their owners against competition from others and by giving the owner a unique position on certain aspects of their business model the possibility to extract rents from them through licensing agreements with others to give them access to the legally protected legal intangibles or through the exclusive right to offer products and processes based on these legal assets which cannot be imitated without violation of the intellectual property rights of their owner. Imitation of successful business models of market leaders is severely impeded if they control legal intangible assets give their owners significant market power to extract rents or deny access.

Globalization, i.e. international free trade in most capital goods and services, makes it more and more easy to buy physical capital in form of equipment and structures at best practice levels everywhere. However, there are non-tradable or limited-tradable goods and services which are closely linked to these intangible assets. Tacit knowledge is another component of intangibles hard to measure in empirical studies. However, all kinds of intangibles are becoming more and more a key assets for establishing a competitive advantage at firm but also at the level of industries, regions and countries.

Companies like Microsoft by owning intangibles like the copyright on the source code of their operating system or their office software package enabled them to become the global hegemon in these areas. Similar effects emerged with companies like Coca Cola with their unique recipe for their soft drink and their global brand image. All kinds of efforts and resources spent on the acquisition of legal intangibles could therefore be considered to be a part of the production process of intangible assets. The present paper just could base the empirical research on the data currently available in the Eurostat Regional Database on indicators innovation activities. This limits our analysis to the state-of-the-art database.

\footnotetext{
${ }^{4}$ Intangible Assets and Regional Economic Growth. See http://www.iareg.org/ .

${ }^{5}$ Intangible Capital and Innovations: Drivers of Growth and Location in the EU See http://www.enepri.org/inno

${ }^{6}$ See for e.g. the survey on different activities by study launched by the DG Enterprise of the European Commission in February 2000 "policy trends in intangible assets" in seven Member States: France, Germany, Italy, Netherlands, Sweden, Denmark and United Kingdom. http://www.ll-a.fr/intangibles/.
} 
The focus of this paper is on the regional dimension of intangible assets by restricting oneself on the regional classification standards agreed in the European Union. The foundation for the division of Europe into the different regions will therefore be the NUTS (Nomenclature des unités territoriales statistiques) systematic by the European Union. The level used will be the NUTS 1 level, which includes 97 regions.

In the first part the simple relationship of Okun's Law was analysed in order to gain a first insight into the data and reveal fundamental properties of the distribution of the growth rate, the per capita GDP and the unemployment ratio, since those are important economic numbers to describe the situation of a country. By concentrating on a very simple model it will hopefully be possible to see underlying geographical structures.

In the second part of the paper the model will be extended to include variables to take into account the intangible assets, like education and research and development.

Because of their importance as an indicator of innovation abilities of a region the effect of patents and the determinants of the number of patents will be analysed separately in the third part.

\section{Methodology}

\subsection{Panel and Cross-section Econometrics}

In empirical analysis cross-section studies of regional data have been common place for a long time. The unit of observation are particular regions like countries, i.e. (NUT 0), or smaller entities even down to the level of single persons or firms. However, the spatial dimension of these data are neglected. While time and autocorrelation over time between economic variables are considered to be important to understand their evolution over time, the spatial dimension have been neglected for a fairly long time in economic analysis.

It is implicitly or explicitly ruled out by assumption that the spatial environment where a firm an individual household are operating and forming their decision about their economic activities does not influence the results of their parameter estimates of the respective models. However, this is a very restrictive assumption which would need testing. At least one could expect that if there are locational interactions leading to spatial dependencies this would lead to inefficient estimates of the underlying nexus between behaviour of economic agents and their spatial distribution over the geographical space.

The debate on the spatial dimension of economics has led since the mid-1990ies to a new section in the economic discipline under the label of new economic geography (see e.g. 
Krugman 1991, Krugman, Venables 1995, Venables 2006). They raised the issue of economics and economic development as a spatial phenomenon as their key research topic. Especially with the increasing integration of before more secluded national economies in the world of more trade liberalization and by this globalization the issue of locational competition and locational competitive advantages has attracted the attention of economics and policy makers alike. Benchmarking regions according to their relative comparative advantages has become an important topic and policies tempting to improve regional disadvantages by often imitating best practice leaders specific institutional and policy settings become a guideline for good policy design. However, neglecting the spatial embeddedness of a comparative regional advantage might lead to misjudgments about the opportunities to successfully imitate successful regional designs. Therefore better understanding of the spatial embeddedness of a region beside its intrinsic regional, i.e. inside the regional available beneficial factors will contribute to a better understanding why the geography of the global economy is evolving towards a highly differentiated locational structure, with agglomeration centers with high income and growth, and regions which tend to fall more and more behind those. The rather naïve view that economic development will tend to equalize the inequality across regions by pure market forces is becoming more and more obvious as a fallacy in economic reasoning. The allocation of activities over the geographical space will not lead in the long-run to a steady state spatial equilibrium. Instead empirical evidence and economic history teach us that there is a continuous dynamic process going on, shifting often dramatically the fortunes from one region to another. Still this dynamics are not well understood by empirical research. This is due to a lack of data for the key driving economic factors on the one hand, but as well by a lack of econometric methods to deal with the specific circumstances to define appropriately an economic space and the co-evolution of economic activities. With the increasing fragmentation of production processes and the exchange of services especially via the Internet in offshore outsourcing new economic factors related to transportation and communication costs are significantly reshaping the structures of spatial comparative advantages (see e.g. OECD 2007, Friedman 2005, Erber, Sayed-Ahmen 2005).

\subsection{Spatial Econometrics}

Analysing effects over different regions in standard panel or cross-section regressions, one assumes implicitly that regions do not interact with another. From an econometric point of view spatial cross-correlations between regions are assumed to be statistically insignificant. Regions interact with each other in their economic activities. For example trough interregional trade and with regard to intangible assets like human capital migration of the labour force play 
an important role. Other factors like capital in particular as financial capital together with intangible assets connect regions with another. Furthermore regions that are geographically close to each other, have a common often have institutions or share common natural and backgrounds, leading to a co-evolution in their economic development.

Thus it can be supposed that the neighbouring regions have an effect on the region itself and the assumption made when estimating the standard OLS estimates is false. This has an effect, depending on the form of interaction, on the quality of the estimates.

This effect has thus to be taken into account when building a model.

In order to find out about the existence of spatial autocorrelation different measurements can be used.

The measure used dominantly in this project is Moran's I. It is based on cross products of the values to assess the similarity of the neighbouring values.

$$
I=\left(N / S_{0}\right) \sum_{i} \sum_{j} w_{i j}\left(x_{i}-\mu\right)\left(x_{j}-\mu\right) / \sum_{i}\left(x_{i}-\mu\right)^{2}
$$

Since this value is not standardised it cannot be interpreted readily concerning strength, direction and significance of the spatial autocorrelation. The standardisation is done by subtracting the mean of the distribution and dividing by the standard deviation. This results in the standardised z-value.

The mean and the standard deviation can be found by different approaches. The software GeoDa used for this analysis employs the permutation method.

In this approach the values observed for the different regions are redistributed randomly over the regions. By calculating the Moran's I statistic for each of those redistributions an artificial reference distribution is computed. This distribution can then be used to standardise Moran's I.

A positive value of the standardised Moran's I indicates positive spatial autocorrelation, and a negative value negative spatial autocorrelation.

The reference distribution can also be used to make decisions about the significance of the statistic by comparing the number of times the distribution created by resampling is equally or more extreme than the distribution actually observed to the total number of permutations. ${ }^{7}$

When introducing this effect in the model there are certain aspects that have to be considered.

\footnotetext{
${ }^{7}$ Luc Anselin, Spatial Data Analysis with GIS: An introduction to application in the social sciences, Technical Report, August 1992
} 
The region Belgium 1 for example will not be influenced by all the other 96 regions, but only by certain other regions. The choice of the regions that are assumed to significantly influence one region is based on nearness.

There are basically two different approaches to measuring nearness. One is to base it on distance and consider all regions within a certain distance to have a significant influence, the other to base it on a shared border, i.e. consider only the neighbouring regions to be influencing the region itself.

The approach taken in this analysis for the EU27 region is contiguity based. Results for a distance based matrix a reported for completeness in some cases in order to show the effect of the choice of the weight matrix.

This is made operational by the so called Weight Matrix $W$. The weight matrix for the contiguity based approach consists of $\mathrm{N}$ rows and $\mathrm{N}$ columns, with $\mathrm{N}$ equal to the number of regions. It is binary and consists only of 1 , in case the regions are neighbours, or 0 , in case they are not.

The form of influence that the regions have on each other is another aspect that has to be thought about.

There are basically two ways a regions can influence the other one.

The ordinary regression model for the regions is:

$y=\alpha+\beta X+\varepsilon$

where $\mathrm{y}$ is a $\mathrm{Nx} 1$ vector for the explained variables of the respective regions, $\mathrm{X}$ is a matrix with all explanatory variables and $\beta$ the coefficient vector and $\varepsilon$ is the vector of the error term. When introducing the effect of the neighbouring regions, this effect can either be modelled by the spatial error model or the spatial lag model.

The spatial error model assumes that there is no substantial autocorrelation in between the regions but that the shock on one region, i.e. the error term, is also felt by the neighbouring regions.

$y=\alpha+\beta X+\varepsilon$ with $\varepsilon=\lambda W \varepsilon+v$, where $v$ is a well behaved error term (see Anselin 1992).

If this effect is ignored the OLS estimates will be unbiased but inefficient, since the assumption of no serial autocorrelation in the error term is violated. 
The spatial lag model does take into account the possibility of substantial autocorrelation between the regions (see Fingleton, López-Bazo, 2006)..

$y=\alpha+\beta X+\not y+\varepsilon$

This model assumes that the value of the explained variable in the neighbouring regions has a significant influence on the value that is observed in the region itself.

If this effect is ignored and a simple OLS estimator is used, the estimates will be biased, since relevant explanatory variables are left out.

In order to discriminate between these two models the Lagrange Multiplier-error and LM-Lag test statistic, respectively the robust versions of them, can be used.

The LM error test is calculated in the following way:

$L M_{E R R}=\left(e^{\prime} W e / \sigma^{2}\right)^{2} / \operatorname{tr}\left(W^{\prime} W+W^{2}\right)$, where the variance is substituted by its estimate e'e/N (see e.g. Anselin 1992). e is the vector of the residuals of a regression model estimated by standard OLS. This test statistic is asymptotically $\chi^{2}$ distributed with one degree of freedom, if the residuals are normally distributed.

Examining the test statistic closely one notices a close relationship with Moran's I, the numerator of Moran's I squared and multiplied by $\mathrm{N}$ will equal the numerator of the $\mathrm{LM}_{\mathrm{ERR}}$ statistic.

The formula for the LM-Lag test statistic is:

$L M_{L A G}=\left(e^{\prime} W y / \sigma^{2}\right)^{2} /\left\{(W X b)^{\prime} M W X b / \sigma^{2}+\operatorname{tr}\left(W^{\prime} W+W^{2}\right)\right\}$ with $M=I-X\left(X^{\prime} X\right)^{-1} X^{\prime}$,

$\mathrm{b}$ the vector of the OLS estimates and e and $\sigma^{2}$ defined as above. Again this test statistic follows asymptotically a $\chi^{2}$ distribution with one degree of freedom (Anselin 1992).

When comparing the numerators of the two statistics, one can observe that once the cross product of the error terms is used and once the cross product between the error terms and the dependent variable, i.e. the $\mathrm{LM}_{\mathrm{ERR}}$ checks for correlation in between the residuals and the $\mathrm{LM}_{\mathrm{LAG}}$ for correlation between the residuals and the dependent variable.

Thus the decision whether a spatial error or a spatial lag model is appropriate can be based on these test statistics, respectively their robust forms.

The model should be chosen, which test statistic is more significant, i.e. has the lower pvalue. If both of those test statistics are significant, the model whose robust test statistic is more significant should be chosen. 
When checking for the goodness of fit of the Spatial lag or error model one has to take into account that the $\mathrm{R}^{2}$ is not appropriate to compare spatial models with OLS models, since the $\mathrm{R}^{2}$ reported in the spatial model output is just a pseudo $\mathrm{R}^{2}$ which is not comparably to the regular $\mathrm{R}^{2}{ }^{8}$.

Instead the generally known measures like Log-Likelihood statistic, Akaike Information criterion (AIC) or Schwarz criterion (SC) should be used in order to compare the fit of the model.

\section{Data description and analysis}

\subsection{Data sources and material}

The main data source used was the EuroStats regional data bank.

The data was collected on the NUTS 1 level, which results in a panel of 97 regions over a time period which varies depending on data availability. In general most of the time series were only available for a relatively short period. The panel was set to include the series from 1995 to 2005, which however was scarcely filled by any series.

While data for standard variables concerning GDP and the labour force was available in good quality, the data availability for the intangible assets like e.g. research and development expenditure or human resources in science and technology was often incomplete. In particular the new member countries of the Eastern enlargement have often problems to report these data. However, even long-term EU-member countries like the UK have no official regionalized data for some intangible assets indicators like the number of scientist and engineers by region. Furthermore data for different indicators of intangible assets are often available with significantly different time lags. In particular patent data have the most significant delay in comparison to other data. This makes it difficult to address the actual situation when such variables are included in the analysis (see e.g. OECD 2007).

Information about the number of registered patents is relatively complete, but the numbers are only reliable up to the year 2002 after which the numbers are provisional. These provisional numbers differ widely from the final numbers reported for the earlier years which make them unfit to be used in estimation or analysis.

In the case of missing data the observation was ignored in the analysis, while the other observations for this region were still included, i.e. an unbalanced panel was used. 
For the panel analysis the statistical software EViews was used.

\subsection{Empirical analysis of Okun's Law and distribution of GDP growth in Europe}

\subsubsection{Descriptive statistics}

\section{Descriptive statistics per capita GDP}

The per capita GDP is higher in the north western regions of Europe, especially around the main cities like Brussels, London, Paris and Hamburg. On the other side one can observe that the growth rate of the GDP is remarkably higher in the eastern European states, like Romania and Poland.

\section{Table 1 - GDP per capita}

\section{Top Ten}

\begin{tabular}{|lrl|}
\hline lu0 Luxemburg (Grand-Duché) & 59.78 \\
be1 Région de & $\begin{array}{r}\text { Bruxelles- } \\
\text { Capitale/Brussels }\end{array}$ & 55.61 \\
Hewest & Hoofdstedelijk & \\
de6 Hamburg & & \\
uki London & 45.09 \\
fr1 Île de France & 44.58 \\
fi2 Åland & 41.44 \\
ie0 Irland & 36.95 \\
dk0 Dänemark & 36.64 \\
de5 Bremen & 36.34 \\
se1 Östra Sverige & 35.99 \\
\hline
\end{tabular}

Bottom Ten

\begin{tabular}{|ll|}
\hline pl4 Pólnocno-Zachodni & 5.37 \\
lt0 Litauen & 5.26 \\
& \\
p15 Poludniowo-Zachodni & 5.21 \\
lv0 Lettland & 4.81 \\
pl6 Pólnocny & 4.79 \\
pl3 Wschodni & 3.84 \\
ro3 Macroregiunea trei & 3.53 \\
ro1 Macroregiunea unu & 2.82 \\
ro4 Macroregiunea patru & 2.76 \\
ro2 Macroregiunea doi & 2.20 \\
\hline
\end{tabular}




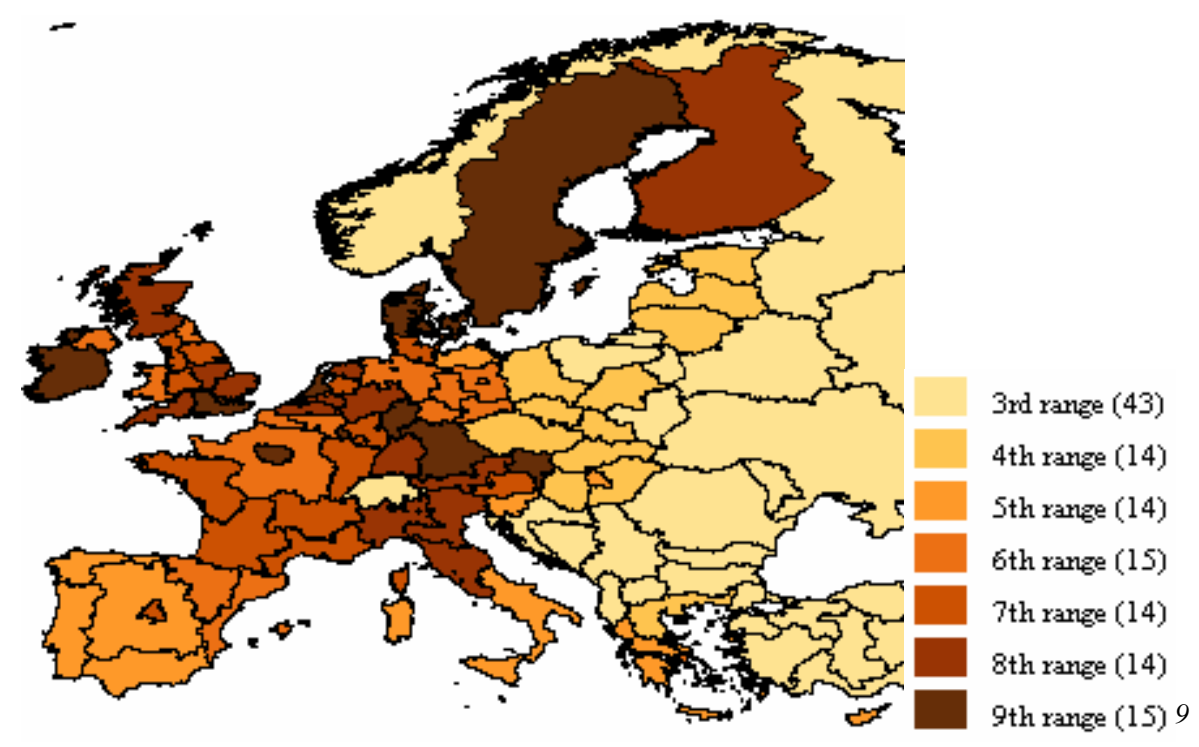

The histogram of the distribution of the per capita GDP can be seen below. The distribution has, probably since the entry of the eastern European countries in 2005 respectively 2007, a rather heavy left tail, representing a higher density of regions with a low per capita GDP.

Figure 2 - Histogram of the per capita GDP

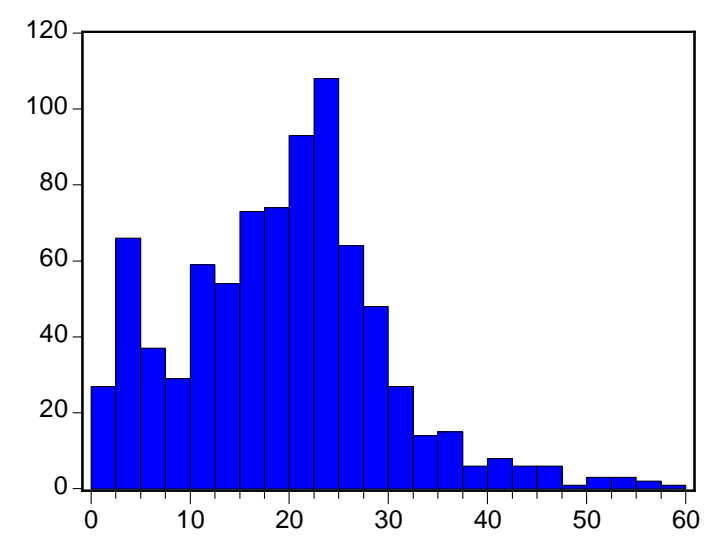

The spread between the regions can be displayed graphically by a boxplot. The boxplot shows the median, the $25 \%$ - and $75 \%$-quantile, as well as the $5 \%$ - and $95 \%$-quantile.

\footnotetext{
${ }^{9}$ Quantile map with 9 ranges, where the first two regions are empty due to the biasing effect of the "zero" for countries for which no data is available. These regions are in the $1^{\text {st }}$ range which has any regions in it. The number in brackets shows the number of regions that fall within this range.
} 
Figure 3 - Boxplot of the per capita GDP for selected countries

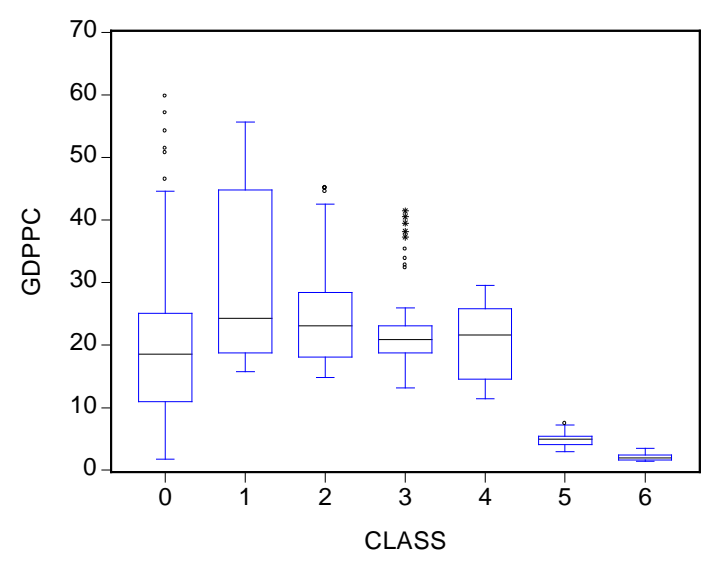

Legend:

0 : EU27

$1:$ Belgium

2 : Germany

3 : France

4 : Italy

5 : Poland

6 : Romania

It is remarkable that the spread in the Western European countries is far bigger than in the Eastern European countries.

In Belgium there is a significant difference between the three regions. Brussels has one of the highest per capita income in Europe, while Wallonia is among the poorer regions in Europe (rank 56 out of 95).

A similar effect can be observed in France, where the strong centralisation leads to a huge difference between the level of the per capita GDP in Paris-Ile de France and the rest of the country. Looking at the boxplot of France, the width between the $25 \%$ and the $75 \%$ quantile is not very wide, representing rather small difference between the majority of regions, while the far outliers represent certain regions, like the region around Paris, which are far wealthier.

In Italy, when taking into consideration the geographical distribution of the regions, the North-South divide is strongly discernible.

In Germany the GDP per capita in the new Bundesländer, i.e. the former GDR, is still significant lower than in the west, in the mean the difference is about $-9900 €$.

\section{Descriptive statistics growth rate of the GDP}

The four regions of Romania are all among the five fastest growing regions in Europe. The other fast growing regions are also almost exclusively in Eastern Europe, while the already wealthier regions in Western Europe suffer from low growth rates. 
Table 2 - GDP per capita growth rate (year 2004)

\section{Top Ten}

\begin{tabular}{ll|}
\hline ro2 Macroregiunea doi & $6.70 \%$ \\
ro4 Macroregiunea patru & $6.64 \%$ \\
ro3 Macroregiunea trei & $6.56 \%$ \\
sk0 Slowakei & $6.38 \%$ \\
ro1 Macroregiunea unu & $5.80 \%$ \\
lv0 Lettland & $5.08 \%$ \\
hu3 Alföld és Észak & $4.86 \%$ \\
ee0 Estland & $4.45 \%$ \\
& \\
lt0 Litauen & $4.42 \%$ \\
hu1 Közép-Magyarország & $4.14 \%$ \\
\hline
\end{tabular}

Bottom Ten

\begin{tabular}{|ll|}
\hline de7 Hessen & $0.65 \%$ \\
n11 Noord-Nederland & $0.63 \%$ \\
de5 Bremen & $0.62 \%$ \\
de6 Hamburg & $0.55 \%$ \\
def Schleswig-Holstein & $0.53 \%$ \\
de9 Niedersachsen & $0.42 \%$ \\
de3 Berlin & $0.37 \%$ \\
pt3 Região Autónoma da Madeira & $0.36 \%$ \\
(PT) & \\
fi2 Åland & \\
mt0 Malta & $-0.03 \%$ \\
\hline
\end{tabular}

Figure 4 - GDP growth rate

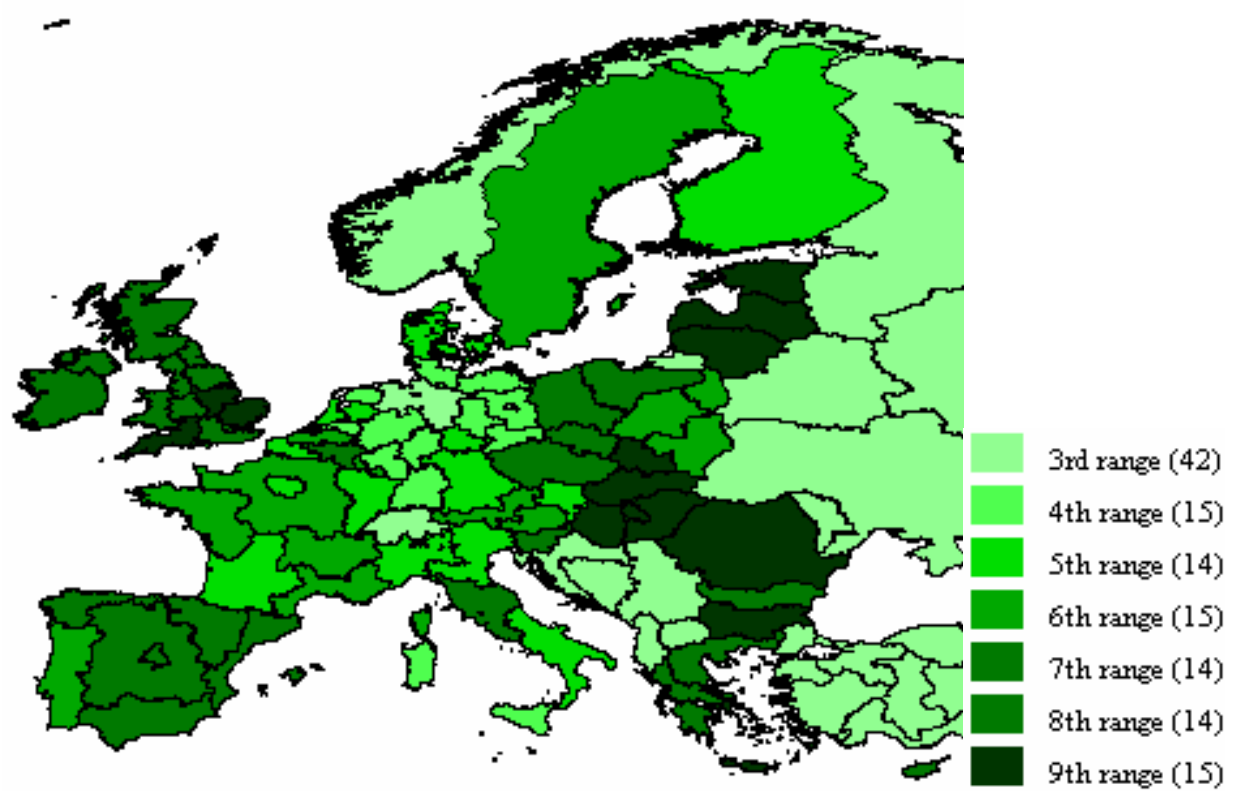

There are often said to be two main "borders" in Europe. On the one hand the north south divide and on the other hand the division between the countries of the former UdSSR and the western countries.

Testing for the significance of these effects by creating dummies, the result is that in the mean the per capita GDP is about 6,000€ lower for the southern countries and 17,500€ lower for the eastern European countries.

When testing for a significant difference between the growth rates of these poorer countries and the wealthier countries, one gets different results. While the eastern European countries have a growth rate which is almost 4 percent points higher than that of their western neighbours, there is no significant difference between the southern and the northern countries. 


\section{Catching up effect}

In addition to these geographical division there seems to be an inverse relationship between the per capita GDP and the growth rate of the GDP, which can be tested by first regressing the growth rate on the level of the per capita GDP and then doing a hypothesis test on the sign of the coefficient.

The result of this test is as expected that there is a significant, negative relationship between the growth rate and per capita GDP. If the GDP per capita is $1,000 €$ higher, the growth rate will, in the mean, be about $0.23 \%$ lower.

This catching up effect will eventually lead to a narrowing in the gap between the countries of the EU27.

But taking into account the result obtained above, this catching up does not happen everywhere with the same strength. The gap between eastern and western Europe closes faster than that between the north and the south of Europe.

It is to be expected that the per capita GDP is spatially autocorrelated, since when looking at the ranking of the per capita GDP there seems to be a cluster of low per capita GDP in the Eastern European countries and a cluster of high per capita GDP in Western Europe, i.e. a positive z-value of Moran's I is expected.

This is confirmed by the Moran scatterplot which displays the per capita GDP on the $\mathrm{x}$ axis and on the $y$ axis the vector of the per capita GDP multiplied with the weight matrix, i.e. the weighted average of the per capita GDP of the neighbouring regions. 


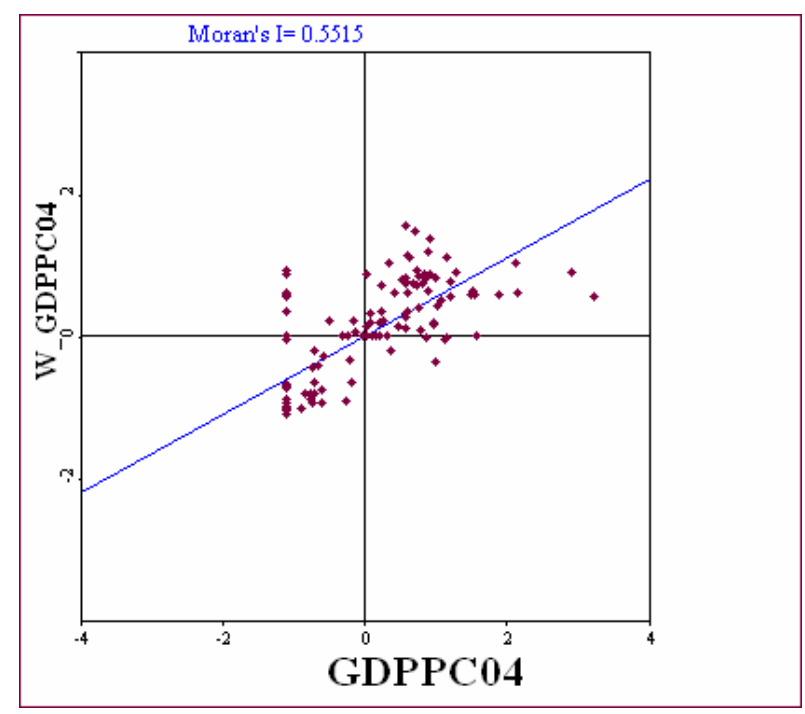

When testing on the significance of the z-value the obtained p-value is 0.001 .

The presence of spatial autocorrelation implies that spatial regression should be used, since one otherwise does not use available information and one runs the risk of calculating biased estimates.

When looking at the measures of the LM-lag and LM-error test statistics, the decision will be in favour of the spatial error model, since while both of the regular test statistics are highly significant, the robust version of the LM-lag test is insignificant while the robust version of the LM- error statistic stays significant.

This implies that there is no substantial spatial autocorrelation in the data. The per capita GDP is not influenced by the values of the per capita GDP in the neighbouring regions but it is only by the shocks, i.e. the error term, that the value of the GDP in these regions will be influenced.

When estimating the model $\lambda$ is highly significant.

The measures of the goodness of fit like the log likelihood measure or the AIC improve significantly, the log likelihood rises from -233.94 to -205.31 and the AIC decreases from 471.88 to 414.62 , which both imply that the spatial error regression fits the data better.

As mentioned above the presence of this kind of spatial autocorrelation does not lead to a bias in the OLS estimates. This can be checked by testing the hypothesis $\mathrm{H}_{0}: \mathrm{b}_{\mathrm{OLS}}=\mathrm{b}_{\text {err }}$.

The t-value of this two sided equality test is $(0.0317668-0.03703473) / 0.00956451=-$ 0.55077887, which does clearly not lead to a rejection of the null hypothesis. 
Consequently the estimates obtained in the ordinary regression are unbiased, but the standard errors are calculated incorrectly, which makes interpretations about the significance of these estimates unreliable.

When comparing the standard errors calculated by OLS and the spatial regression model, the standard errors of the spatial regression model are smaller. The spatial error model uses the information about the geographical correlation in order to improve the estimation, i.e. the estimates are more reliable since more of the available information is also actually used in the estimation procedure.

The implication of this is that the panel OLS estimations are rather conservative, tending to overestimate the uncertainty of the estimation, which will lead to the non rejection of the $\mathrm{H}_{0}$ in some cases where the $\mathrm{H}_{1}$ is actually to be accepted.

While the differences in between the countries seem to be narrowing due to higher growth rates in the less developed countries, this effect does not apply inside the countries.

In the wealthier countries the differences in between the regions are greater, which might indicate a growth of some regions on the expense of other regions in the same country.

Regressing the growth rate of the GDP on the per capita GDP for France, the coefficient is positive (significant on the $10 \%$ level). The implication is that in France the differences between the region continue to grow, since the regions with an already higher per capita income also have higher growth rates, which will lead to an even stronger centralisation.

For Belgium, the country which already faces the biggest differences in between the regions, this effect can also be verified. If the region has a per capita GDP which is $1000 €$ higher, the growth rate will in the mean be $0.34 \%$ higher.

The effect is especially strong in Germany with a coefficient of about 0.44 , which means that the gap between the former GDR and the old Länder does not vanish, to the contrary it widens.

When testing on this effect for some of the eastern European countries, the coefficient is positive, but insignificant. This does not allow any statements to be made with sufficient certainty.

\section{Descriptive statistics unemployment ratio}

The states with the lowest unemployment rate can be found in western Europe, e.g. Austria and UK, while the eastern European countries suffer from rather high unemployment rates. 
Table 3 - Unemployment ratio (year 2006)

Top Ten

\begin{tabular}{|ll|}
\hline at3 Westösterreich & $3.30 \%$ \\
itd Nord Est & $3.60 \%$ \\
n12 Oost-Nederland & $3.70 \%$ \\
n14 Zuid-Nederland & $3.70 \%$ \\
ukk South West (ENGLAND) & $3.70 \%$ \\
dk0 Dänemark & $3.90 \%$ \\
& \\
& \\
itc Nord Ovest & $3.90 \%$ \\
n13 West-Nederland & $3.90 \%$ \\
at2 Südösterreich & $4.10 \%$ \\
ie0 Irland & $4.40 \%$ \\
\end{tabular}

\section{Bottom Ten}

\begin{tabular}{|c|c|c|}
\hline $\mathrm{P}$ & & 15.3 \\
\hline g Thüringen & & $15.6 \%$ \\
\hline 5 Poludniowo-Zach & dni & $16.4 \%$ \\
\hline 4 Brandenburg & & $16.5 \%$ \\
\hline hsen & & $16.6 \%$ \\
\hline égion & lles- & $17.6 \%$ \\
\hline $\begin{array}{l}\text { apitale/Brussels } \\
\text { ewest }\end{array}$ & ffdstedelijk & \\
\hline en-Anhalt & & $17.8 \%$ \\
\hline & & $18.7 \%$ \\
\hline cklenburg-V & 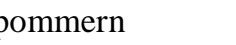 & $19.2 \%$ \\
\hline $\begin{array}{l}\text { anzösische } \\
\text { ttemente (FR }\end{array}$ & überseeische & $27 \%$ \\
\hline
\end{tabular}

Figure 6- Unemployment ratio

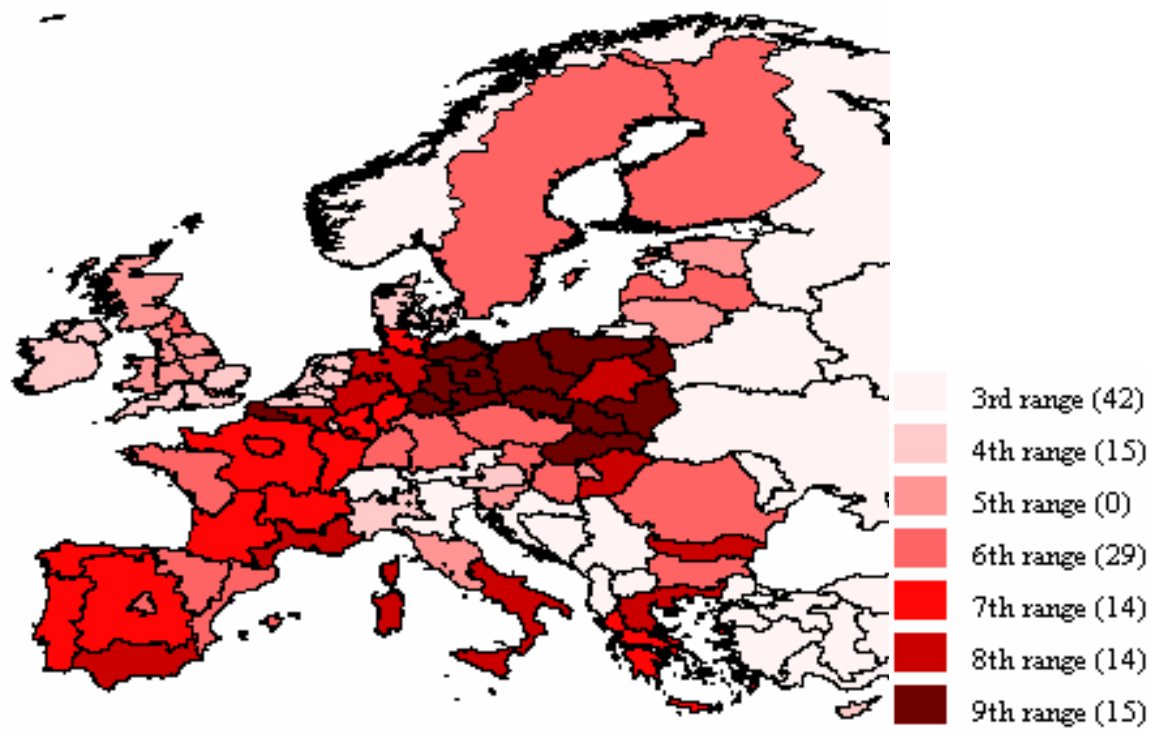

But there are some non expected observations to be made.

One surprising observation is that the region with the second highest per capita GDP in Europe, Brussels, is among the regions with the highest unemployment rate (ranking 91 out of 95 in 2006).

The phenomenon of high per capita income and high unemployment rate also exists in many of the other main cities, which are mentioned above. This is probably due to the suburbs of the city, which in many cases experience a very high unemployment ratio.

In Austria another unexpected observation is that the region, while having some of the lowest unemployment rates in Europe, cannot be found among those with the highest per capita GDP. Also within the country there seems to be an inverse relationship between the per capita GDP and the unemployment rate, the region with the lowest unemployment having the lowest per capita GDP as well. 


\subsubsection{Regression estimations}

Okun's Law describes the relationship between the change in the unemployment ratio and the growth rate of the real GDP.

Table 4 - Change in the unemployment ratio

Top Ten
\begin{tabular}{|ll|}
\hline pl5 Poludniowo-Zachodni & -5 \\
pl4 Pólnocno-Zachodni & -4.8 \\
pl6 Pólnocny & -4.4 \\
pl2 Poludniowy & -3.9 \\
pl1 Centralny & -3 \\
sk0 Slowakei & -2.9 \\
lt0 Litauen & -2.7 \\
itg Isole (IT) & \\
pl3 Wschodni & -2.6 \\
Dee Sachsen-Anhalt & -2.5 \\
& -2.5 \\
\hline
\end{tabular}

\begin{tabular}{|c|c|}
\hline ren & \\
\hline ro2 Macroregiunea doi & 0.6 \\
\hline ukh Eastern & 0.7 \\
\hline ukl Wales & 0.7 \\
\hline hu3 Alföld és Észak & 0.7 \\
\hline uki London & 0.8 \\
\hline fr9 Französische & 0.9 \\
\hline Departemente (FR) & \\
\hline ukf East Midlands (ENGLAND) & 0.9 \\
\hline pt3 Região Autónoma da Madeira (PT) & 0.9 \\
\hline uke Yorkshire and The Humber & 1.1 \\
\hline $\begin{array}{l}\text { be1 Région de Bruxelles-Capitale/Brussels } \\
\text { Hoofdstedelijk Gewest }\end{array}$ & 1.3 \\
\hline
\end{tabular}

Following the argumentation of Okun's Law the countries with high growth rates should also experience a diminishing unemployment rate.

In order to make statements about this relationship which can be empirically verified a regression can be used.

When looking at the time series one notices that the GDP series possesses a unit root.

Formal tests on the presence of a unit root, like for example the augmented Dickey Fuller test, confirm this.

This means that the GDP series is autocorrelated with the coefficient one with its past values. This makes the series a non stationary series.

Since non stationary series cannot be analysed with the standard procedures of time series analysis, it is advisable to take the first level differenced series of the GDP, which is stationary.

Consequently one should regress the logarithm of the GDP on the differenced value of the unemployment ratio. If Okun's Law holds the value of the coefficient should be negative and significant.

Okun's Law, when regressing over all regions and all periods, cannot be confirmed. The coefficient shows the wrong sign, however is also not significant. This might be a hint that 
there are big differences in between the regions, which leads to greater uncertainty when estimating the coefficient.

Using country dummies to show the different effect of the change in the unemployment rate in the countries and allowing for cross section fixed effects, one can observe that the GDP growth is positive correlated with the unemployment rate in the less developed countries, while Okun's Law holds true in the more industrialised countries.

To verify this apparent division between East and West one can divide the European Union in two parts by creating a dummy variable for the eastern European countries.

The result of the regression of the logarithm of the GDP on the change in the unemployment rate as well as a constant dummy and an interaction dummy, confirms the first observation. While the effect of the change in unemployment in general is about -0.9 , for the eastern European countries it is 1.8 higher, which means Okun's Law cannot be empirically verified for this region.

This can be due to a strong inflow of capital, which lowers the need for employees by increasing the productivity per person. Also the introduction of best practices by international companies investing in these countries helps in improving the effectivity of labour.

The effect that can be observed on the macro level in the EU27 can also be observed in a similar form within Germany. When dividing the country in the eastern part, the former GDR, and the western part, this simultaneous growth of the GDP and the unemployment rate can be seen in the eastern part.

In order to check the model for possible misspecifications a residual analysis is helpful, since this reveals underlying patterns or other unwanted characteristics in the residuals, which indicate an inappropriate model.

The descriptive statistics of the residual series are helpful when trying to detect any problems in the residual series. 
Figure 7 - Descriptive statistics of the residual series

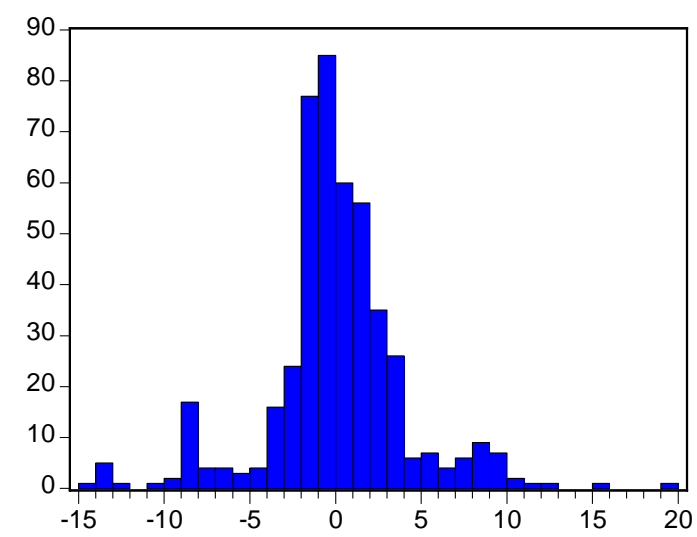

\begin{tabular}{|lr|}
\hline \multicolumn{2}{|l|}{ Series: RESID_OKUN } \\
Sample 1995 2009 \\
\multicolumn{2}{l|}{ Observations 466} \\
Mean & $-4.53 \mathrm{e}-16$ \\
Median & -0.163523 \\
Maximum & 19.65256 \\
Minimum & -14.17795 \\
Std. Dev. & 4.091992 \\
Skewness & -0.031597 \\
Kurtosis & 6.067581 \\
& \\
Jarque-Bera & 182.7894 \\
Probability & 0.000000 \\
\hline
\end{tabular}

The residuals have a mean close to zero, which means that on average the model fits the data correctly.

The residuals are however not normally distributed; the formal test on normal distribution the Jarque Bera test has a p-value of 0 .

This however has no grave implications since the assumption is only necessary for the test statistics, which however still hold asymptotically in large samples.

The graph of the residuals might be used to draw conclusions about the presence of heteroscedasticity.

\section{Figure 8 - Residual graph}

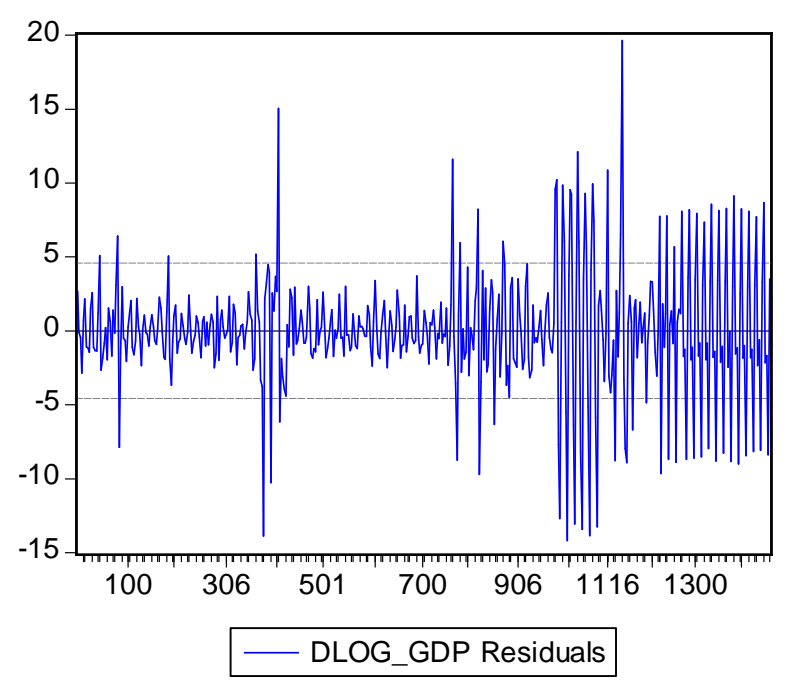

This residual graph clearly indicates a severe heteroscedasticity problem. The later observations seem to have a far greater variance than the first observations. 
This is to be expected from the regression results. These indicate a significant difference between East and West Europe in almost all areas. Thus it is plausible that the residuals should also have a different variance. A variance equality test for the residual series for differences between East and West Europe confirms this. The difference is highly significant with a p-value of 0.000 .

When just dividing the sample in half and repeating this test, the result indicates again unequal variances which implies not only differences in between East and West but also in the Eastern and Western regions itself.

The heteroscedasticity is probably due to differences between the regions, which are already shown clearly by the coefficient estimates when dividing the sample into subsamples.

This assumption is affirmed when repeating the test on variance equality for the regressions done for the subsamples.

For the regression for Germany for example the standard deviations of the residual series when dividing it into two subsets are 1.3393 and 1.5005 which is not significant different. The same can be said for France (p-value 0.9847), Hungary (p-value of 0.4587) and Poland (pvalue of 0.9690 ) for example, where the p-value belongs to the F-test on variance equality with the $\mathrm{H}_{0}: \sigma_{1}=\sigma_{2}$.

The subsample regressions are consequently reliable and do not suffer from heteroscedasticity, while the panel estimation does.

The heteroscedasticity problem could be solved by using the generalised method of moments (GMM) estimator, which would take into account the heteroscedasticity in the estimation procedure and thus calculate correct standard errors for the coefficients.

Another approach is to use spatial regression which might take care of the heteroscedasticity.

In this analysis the second approach is used.

The third assumption about the residual is their independence, i.e. their noncorrelation. The presence of spatial spill over effects however will by definition lead to such a dependency when ignoring this effect as was done in the panel estimation above.

Repeating the regression with the inclusion of spatial effects should solve this problem as well as the heteroscedasticity problem and thus produce residuals which possess the desired characteristics. 


\section{Okun's Law with spatial autocorrelation effects}

Calculating Moran's I z-value to determine whether the growth rate of the GDP is spatially autocorrelated affirms this assumption. The z-value of 0.4315 is highly significant and indicates positive spatial autocorrelation.

To determine which kind of spatial autocorrelation is present, the LM test statistics are again helpful.

In the years 2000 and 2001 the robust versions of the statistics are not significant while the ordinary versions are. This points to some kind of misspecification in the basic model. ${ }^{10}$

Analysing the various test statistics as well as the residual plot, a misspecification problem could however not be found.

In 2002 and 2003 the appropriate regression model is the spatial error model, indicating that there is no substantial spatial autocorrelation.

In 2004 however the test statistics imply that there is substantial spatial autocorrelation present, i.e. that the spatial lag model is the correct choice.

The estimated spatial lag model for the year 2004 is:

\section{REGRESSION}

\section{SUMMARY OF OUTPUT: SPATIAL LAG MODEL - MAXIMUM LIKELIHOOD ESTIMATION Data set : nuts1}

Spatial Weight : NUTS1.GAL

Dependent Variable : DLOG_GDP04 Number of Observations: 129

Mean dependent var : 1.67806 Number of Variables : 3

S.D. dependent var : 1.54683 Degrees of Freedom : 126

Lag coeff. (Rho) : 0.844054

R-squared : 0.355220 Log likelihood : -212.923

Sq. Correlation : - $\quad$ Akaike info criterion : 431.846

Sigma-square : 1.54275 Schwarz criterion : 440.425

S.E of regression : 1.24207

\begin{tabular}{cccccc} 
Variable Coefficient & Std.Error & z-value & Probability \\
\hline W_DLOG_GDP04 & 0.8440544 & 0.03967452 & 21.27447 & 0.0000000 \\
CONSTANT & 0.3291349 & 0.1329844 & 2.47499 & 0.0133240 \\
DUEMQ04 & -0.06336215 & 0.1399061 & -0.4528904 & 0.6506277
\end{tabular}

\footnotetext{
${ }^{10}$ Luc Anselin; Exploring Spatial Data with GeoDa: A Workbook
} 
In comparison the model estimated by OLS:

\section{REGRESSION}

SUMMARY OF OUTPUT: ORDINARY LEAST SQUARES ESTIMATION

Data set : nuts1

Dependent Variable : DLOG_GDP04 Number of Observations: 129

Mean dependent var : 1.67806 Number of Variables : 2

S.D. dependent var : 1.54683 Degrees of Freedom : 127

R-squared : 0.023144 F-statistic $\quad: 3.00894$

Adjusted R-squared : 0.015452 Prob(F-statistic) : 0.0852331

Sum squared residual: 301.511 Log likelihood : -237.803

Sigma-square : 2.3741 Akaike info criterion : 479.606

S.E. of regression : 1.54081 Schwarz criterion : 485.326

Sigma-square ML : 2.33729

S.E of regression ML: 1.52882

\begin{tabular}{crrrr} 
Variable & Coefficient & Std.Error & t-Statistic & Probability \\
\hline CONSTANT & 1.713138 & 0.1371597 & 12.4901 & 0.0000000 \\
DUEMQ04 & -0.3010537 & 0.1735552 & -1.734629 & 0.0852331
\end{tabular}

As expected the coefficient in the spatial lag model is significantly smaller (t-value of 1.3695 when testing $\mathrm{H}_{0}$ : $\mathrm{b}_{\mathrm{OLS}}>\mathrm{b}_{\text {lag }}$ ), indicating that some of the supposed explanation done by the explaining variable is in fact due to the similarity of the neighbouring regions.

The interpretation of the results is that the weighted average of the neighbouring regions multiplied with 0.844 is the influence of the neighbouring regions on the growth rate of the regions under consideration.

The transition from the spatial error to the spatial lag model might indicate that the ties between the European regions became stronger in recent years. While in earlier years the influence was restricted to the influence on the error term without an influence of the level of the growth rate of the GDP, now the observed level of growth in one region has an influence on the level of growth in the neighbouring regions, which indicates a stronger relation between the regions.

The spatial regression may take care of the heteroscedasticity problem.

In order to check for both versions of the spatial regression, the residual series for the spatial lag model for the data of the year 2004 and the residuals for the spatial error model for the year 2003 were created.

Dividing both series in two subsamples in a way that each contains about half of the data and then calculating the variance for those subsets, shows that there are no significant differences in between the subset-variances for either of the series. 
Residual series of the spatial error model for 2003:

Category Statistics

\begin{tabular}{l|llll}
\hline \hline & & & Mean Abs. & Mean Abs. \\
HALF & Count & Std. Dev. & Mean Diff. & Median Diff. \\
\hline 0 & 64 & 1.425893 & 0.911715 & 0.887619 \\
1 & 65 & 1.175824 & 0.830618 & 0.816210 \\
\hline All & 129 & 1.331913 & 0.870852 & 0.851638 \\
\hline \hline
\end{tabular}

Residual series of the spatial lag model for 2004:

Category Statistics

\begin{tabular}{l|llll}
\hline \hline & & & Mean Abs. & Mean Abs. \\
HALF & Count & Std. Dev. & Mean Diff. & Median Diff. \\
\hline 0 & 64 & 1.349935 & 0.907342 & 0.896734 \\
1 & 65 & 1.134976 & 0.790575 & 0.783222 \\
\hline All & 129 & 1.246916 & 0.848506 & 0.839538 \\
\hline \hline
\end{tabular}

The differences are in both cases not significant. The p-value for F-test is 0.1274 respectively 0.1701 .

When estimating the spatial regression there are consequently no misspecification problems present any more, so that the results are reliable.

As described above the spatial weight matrix can be defined in different ways. The analysis above was done with the neighbouring matrix which assigns neighbouring regions the weight 1 and none neighbours the value 0 .

Another way to define the weight matrix would be to consider the distance of one region from another one, i.e. each region that is within a certain threshold distance of the centre of the region is assigned a weight that takes into account the actual distance of the regions, each region that does not fall within the threshold distance is not assumed to influence the region and consequently takes on the value 0 .

In order to determine the sensitivity of the results concerning the choice of the weight matrix, the spatial regression was repeated for the year 2004 with a distance based weight matrix. The threshold distance was chosen in a way that each region has at least one neighbour.

The regression results of the OLS estimate do not depend on the choice of the weight matrix while the calculations of the measures of spatial autocorrelation do. 
When using the distance based matrix the spatial autocorrelation is still significant but Moran's I z-value indicates a weaker dependence. The z-value for the neighbouring weight matrix was 0.397 , which indicates rather strong positive spatial autocorrelation, while the value for the distance based matrix 0.099 indicates a weak spatial positive autocorrelation. This is not surprising since many of the regions in central Europe, where the distance between the regions are rather small, now are assigned many more "near" regions which are supposed to have an influence on them and be influenced by them.

The interpretation of the LM-test statistics leads to a different conclusion, the spatial error model instead of the spatial lag model is supposed to fit the data better when using a distance based weight matrix. This also indicates a weaker, respectively a not substantial spatial dependence in the data.

To be able to compare the fit of the spatial models, the spatial error model is estimated once using the distance based and once the neighbouring matrix, even though the LM-test statistics indicate that the spatial lag model is the appropriate model when using the neighbouring matrix.

The log likelihood test statistics indicate that the use of the neighbouring matrix will lead to a higher power of explanation, it rises from -233.18 to -210.64 , which is a significant difference. The AIC and SC criterion lead to the same conclusion.

In general one can observe that the choice of the spatial weight matrix does influence the results substantially, none of the results obtained remained unchanged when changing the applied weight matrix.

In this case, which cannot be generalised, the neighbouring matrix produces a better fit of the spatial models.

This might also be due to the choice of the threshold distance, which might not have been appropriate for many of the regions of Central Europe, which are geographically much closer than the regions in Eastern Europe. In this case however a lower choice of the threshold distance is impossible, since it would result in some regions having no neighbours at all.

One way to avoid this problem would be to use the k-nearest neighbour definition of the weight matrix, which takes the $\mathrm{k}$ regions that are geographically closest to the region itself and assigns them a value which is dependent on their distance from the centre of the region.

To build a spatial regression using the non-symmetric k nearest neighbour matrix is however impossible at the moment (with GeoDa). 


\subsection{Influence of intangible assets on macroeconomic key data}

\subsubsection{Determinants of the growth rate of the GDP: Intangible assets}

While Okun's Law is restricted to the influence of the difference in the unemployment ratio on the growth rate, the growth rate is of course influenced by many more factors.

Some of the factors gaining increasing influence are related to innovation and the education of the labour force. A regression of the growth rate of the GDP on certain factors might help to learn something about the influence of these factors and about the magnitude of these effects.

The number of students relative to the number of the population might have a significant, positive influence on the growth rate of the GDP, since it is assumed that students are able to create more wealth.

This however cannot be shown by a regression probably because the period under observation is too short. The effect of the students will probably only take place relatively long after graduation which is impossible to estimate with the data set at hand (since a long lag will lower the number of observations available for estimation too much to obtain reliable results).

This variable has thus not been included in the model. Instead an instrument variable has been used. The variable lf_eedu_r shows the percentage of the labour force which has a university degree or equivalent. This should be highly correlated with the lagged number of students and thus reflect the influence of a high number of students. 


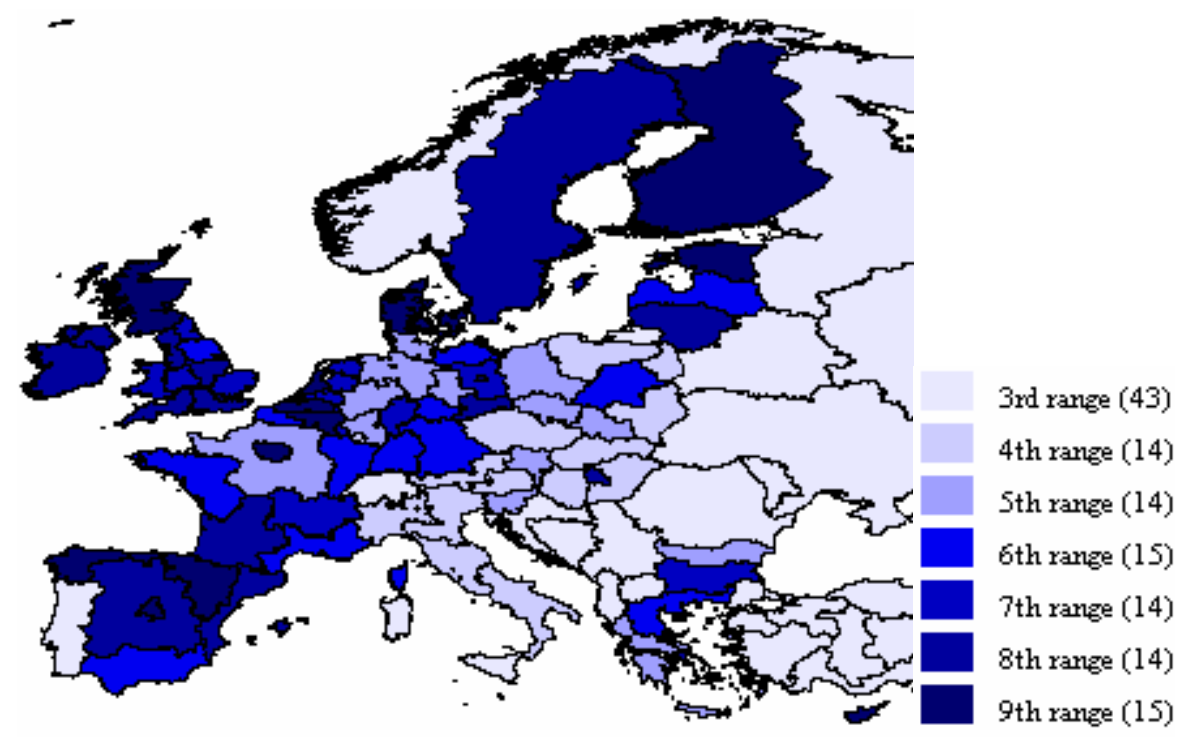

The effect when estimated over the whole data set is positive but insignificant. When dividing the data set in east and west Europe, the coefficient is highly significant and positive for Western Europe, while it is still positive but insignificant for Eastern Europe.

This implies that the effect of higher education is stronger in Western Europe. This might be due to the structure of the economy in Eastern respectively Western Europe. In Eastern Europe the strong growth is mainly based on simple manufacturing jobs, in which no higher education is needed. These jobs however are not profitable in Western Europe due to higher labour costs. Thus the nature of the jobs creating wealth in Western Europe requires better education, which makes the effect of a higher percentage of better educated workers significant in Western Europe.

The expenditure for research and development per person is expected to have a positive impact on the growth rate of the GDP since technological innovation improves the productivity, the competitiveness of products and might even create new industries. 
Figure 10 - Expenditure for research and development per person

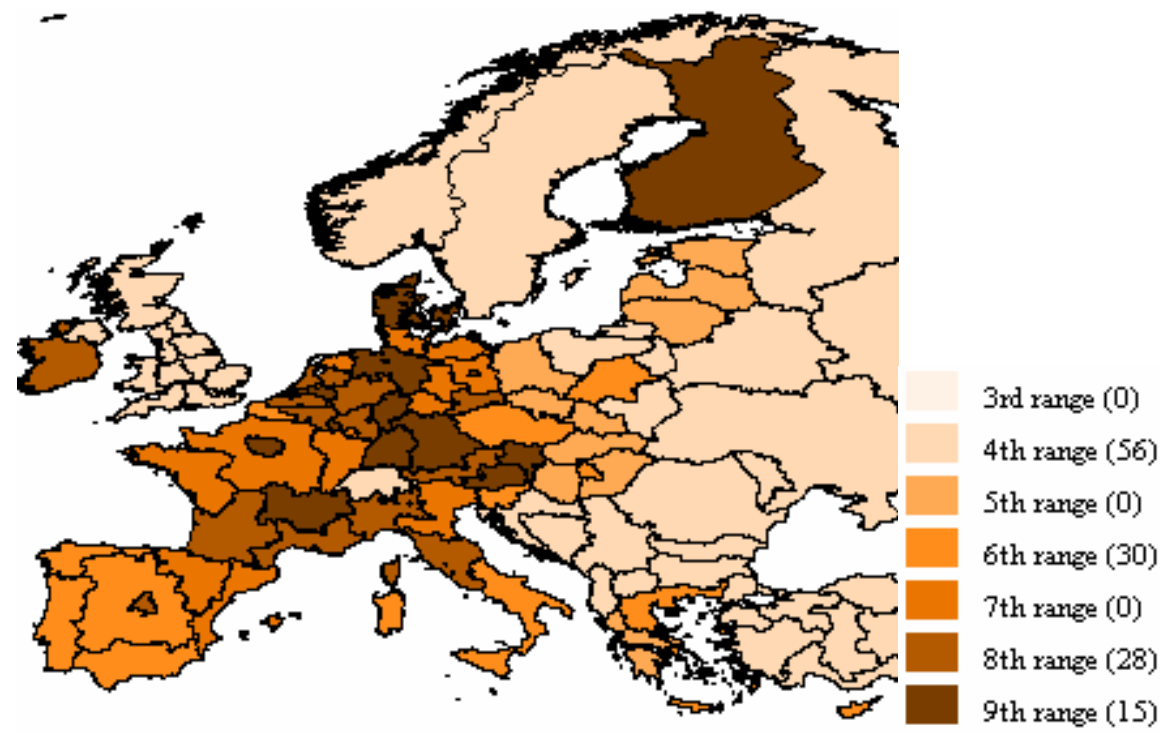

This is confirmed by the regression results. When considering the whole of Europe the effect is positive and significant.

In Eastern Europe the coefficient is higher, implying a stronger effect of research and development on the growth rate of GDP. This might be explained by the fact that the technological level of Eastern Europe is in general still lower than in Western Europe. On this lower level it is comparably easier, i.e. less costly, to improve the productivity.

In Western Europe, while the coefficient is still positive, it is insignificant. One possible reason for this surprising result might be outsourcing. Many companies, while keeping their research and development departments in Western Europe due to better infrastructure and better educated labour force, outsource their manufacturing units in low wage countries. Thus the productivity improving effect as well as the effect of growing competitiveness cannot be felt in the country itself, and the third effect mentioned above might be too small to lead to significant results.

The percentage of the labour force working in the science and technology sector might have a positive influence on the growth rate of the GDP, since their productivity might be higher and their work might have positive effects on the productivity of the remaining labour force. 
Figure 11 - Human resources in science and technology relative to the total labour force

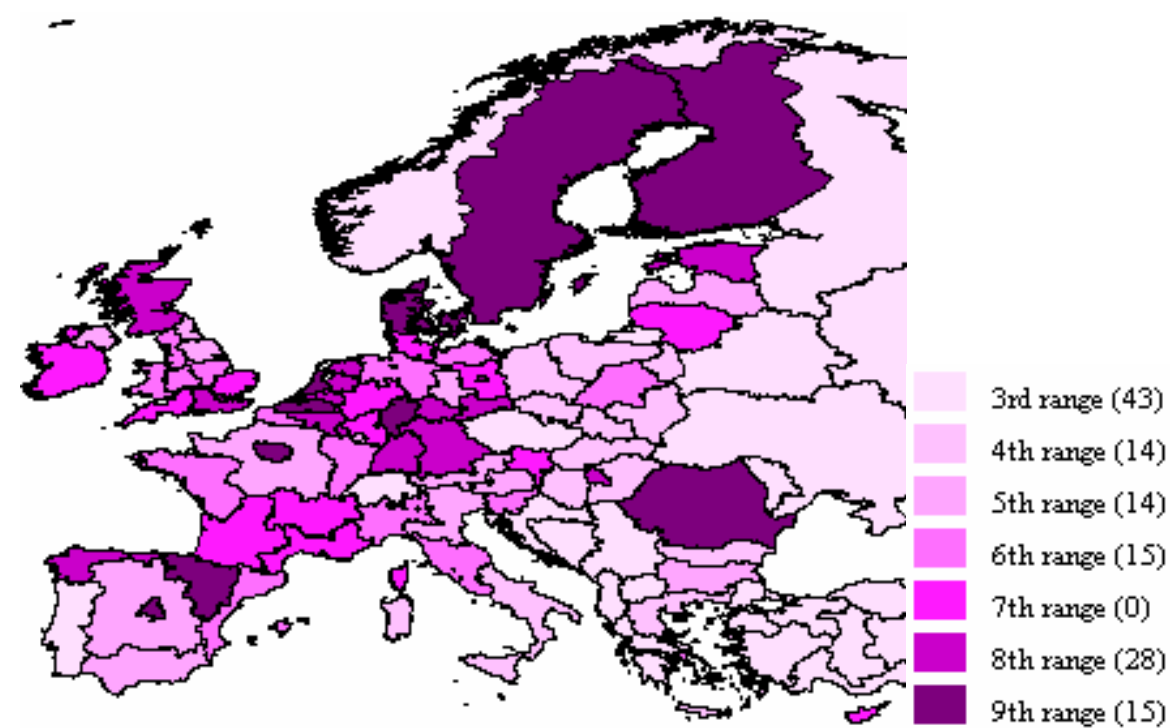

However since the effects might be closely linked to the effects of the research and development expenditure one has to pay attention to problem of multicollinearity, which might lead to problems in the estimation.

To check for this the correlation coefficient can be calculated. The correlation between HRST_R and RAD_R is 0.26 which should not lead to any problems in the estimation procedure.

The coefficient obtained when estimating is however insignificant, though positive. Again there is a difference between Eastern and Western Europe, the effect is positive in both cases, in Eastern Europe however it is insignificant.

The effect of the remaining variable is obvious.

The unemployment ratio has a negative and significant influence on the growth rate of the GDP.

The growth rate of the labour force has a positive impact on the growth rate of the GDP, which is obvious since the new entries into the labour force, provided that they are able to find a job, will enlarge the GDP.

The effect of the level of the per capita GDP is negative, implying that the higher the per capita GDP the lower the growth rate. This will, as explained above lead to a catching up effect of the poorer regions with the richer regions.

The residual analysis shows that the mean of the residuals is not significantly different from 0 . The residuals are however not normally distributed which as explained above does not lead to any major problems. 
As is to be expected the residuals of this regression are heteroscedastic as well when estimating over the whole panel.

For the regression that only concerns Western Europe however the $\mathrm{H}_{0}$ of equal variance cannot be rejected, while it will still be rejected for the Eastern European sample. This implies that most of the variance uncertainty and differences arise from the Eastern European countries. This result differs from the result obtained in the estimation of Okun's Law where there was also significant heteroscedasticity in the Western regions itself.

Again the spatial regression might help to alleviate this problem.

\section{Spatial effects}

Since the regression tries again to explain the growth rate of the GDP and this growth rate is, as shown above spatially autocorrelated, a spatial regression may again give some more information about the nature of the influence and take care about the systematic patterns in the residual.

Additionally it has to be checked whether the influence is substantial and thus biases the regression results above.

Since the spatial error model is again to be preferred, which is consistent with the results for the Okun's Law regression, the spatial dependence is not substantial.

When estimating the spatial error model, the power of explanation increases but it does not lead to new insights concerning the influence of the explaining variables on the growth rate of the GDP. The estimates obtained above are unbiased and the interpretations about the significance are rather conservative since the true standard deviation calculated in the spatial regression is smaller than the one calculated by OLS.

The heteroscedasticity problem has again been taken care of. There is no more sign for significant variance differences in the residual series of the sample. This result does not depend on the different division of the sample into subsamples.

Consequently one can say that by the spatial regression all of the misspecification problems have been taken care of and the residuals do not show any systematic behaviour any more but are basically a white noise series.

Repeating the regression with the distance based weight matrix, there is no significant spatial autocorrelation at all, implying that the OLS estimates are sufficient. 


\subsubsection{Impacts of intangible asstes on the regional unemployment ratios}

The unemployment ratio is one important macroeconomic indicator of the state of an economy. This is true as well for regions.

It is expected that the unemployment ratio respectively the development of the unemployment ratio is influenced by intangible assets like education as well as the growth rate of the GDP.

In order to avoid estimation problems the difference in the unemployment ratio is considered.

The growth of the labour force is expected to influence the change of the unemployment ratio positively, since a fast growing labour force will make it harder to reduce unemployment because the number of jobs newly created will have to exceed the growth rate of the labour force in order to make it possible to decrease the unemployment ratio.

This effect is statistically significant and has the expected sign.

All the results above indicated that an estimation over the whole panel is not appropriate in most cases since there are significant differences between the regions especially between Eastern and Western Europe.

Consequently it should be checked whether this effect is identical for the two parts of Europe.

The regression results show that the effect is not significant in Eastern Europe.

The next variable that was considered is the lagged number of students relative to the whole population. The positive influence of students on the unemployment ratio should be felt faster than their influence on the growth rate of the GDP, since the chance that they will be able to find a job directly after their studies is relatively high compared as to non students, who might face greater difficulties. Also students are not counted as belonging to the labour force which lowers the available labour force and thus the calculated unemployment ratio, which enhances the effect.

For the whole panel the effect is significant and negative, which is the expected outcome.

For Western Europe this result holds, while for Eastern Europe the effect is not significant at all (p-value of 0.79).

There might be two possible reasons for this. One is that the young professionals might encounter greater difficulties at finding an appropriate job after they finish their studies. The other reason might be the so called brain drain, the fact that the students leave their countries after graduation to be able to earn more in the Western European countries. The effect of their education is then consequently not felt at all in their home countries where they studied. 
A higher level of education of the labour force is expected to make it easier to lower the unemployment ratio. This however cannot be shown by the regression. The two variables showing the labour force with a secondary educational degree respectively no degree at all in comparison to the total labour force are not significant (the labour force with a tertiary educational degree was left out as the reference category).

Expenditure for research and development might influence the unemployment ration in two ways and in two directions.

Firstly it might lead to innovations which increase the productivity per worker and thus make it possible to produce the same amount of output with fewer employees, thus increasing the unemployment ratio.

On the other hand it might also lead to the creation of jobs in this sector itself and through new innovations and inventions might lead to new products, eventually even to new industries, which will have a positive impact on the unemployment ratio.

The coefficient for the whole panel is negative but insignificant. The negative sign indicates that on average the second, job creating effect of research and development exceeds the destruction of jobs through automatisation that is brought along by it.

However for East Europe the coefficient is positive, indicating that an increase in research and development expenditure will make it harder to reduce unemployment, consequently that the first effect outweighs the second one. This is easily explainable by the nature of jobs that can mainly be found in Eastern Europe and by the comparable backwardness of their industries. The jobs that are newly created in Eastern Europe are mainly simple manufacturing jobs that are the easiest to replace by automatisation. Also since the machines that are currently working in Eastern Europe are most of the time not on the same level as the machines in Western Europe the increases in productivity can be achieved easier and with less money than when trying to increase the productivity in Western Europe which is already on a higher level. The percentage of the labour force working in the science and technology sector has a highly significant and positive influence.

This is a surprising result. A possible explanation might be that the science and technology sector in general is rather capital intensive than labour intensive. A higher percentage of employees in that sector signifies that this sector is more important in the economy of this regions, thus that the capital intensive industries are more important than the labour intensive industries which might explain the positive sign of the coefficient. 
The effect is not significantly different for East and West Europe.

The level of unemployment has a positive highly significant influence on the change in the unemployment ratio, which implies that when the unemployment ratio is already high it is harder to reduce it. This points to a self reinforcing effect of unemployment.

The last variable is the lagged growth rate of the GDP. The effect of the growth rate of the GDP on unemployment has been discussed in detail above.

It is negative for Western Europe, while it is insignificant for Eastern Europe.

Checking the residuals for signs of misspecification one can observe that heteroscedasticity is present.

The test on variance equality rejects the $\mathrm{H}_{0}$ clearly when dividing the panel in two equal parts. An interesting observation is that the division of the panel in Eastern and Western Europe and then testing on variance equality does not lead to the rejection of the $\mathrm{H}_{0}$, which indicates that there are differences between the variance for each region but that the differences do not follow some kind of spatial pattern with respect to the east-west geographical location.

When repeating the regressions for each region separately, the coefficients turn out to be insignificant because of lack of data.

The residuals however of the regions are homoscedastic, e.g. for Germany the p-value of the F-test on variance equality is 0.57 , for Poland it is 0.46 .

The change in the unemployment ratio is highly spatially autocorrelated. Moran's I z-value of the change in the unemployment ratio in the year 2006 is 0.57 , which is highly significant.

Figure 12 - spatial autocorrelation of unemployment rate and change of unemployment rate

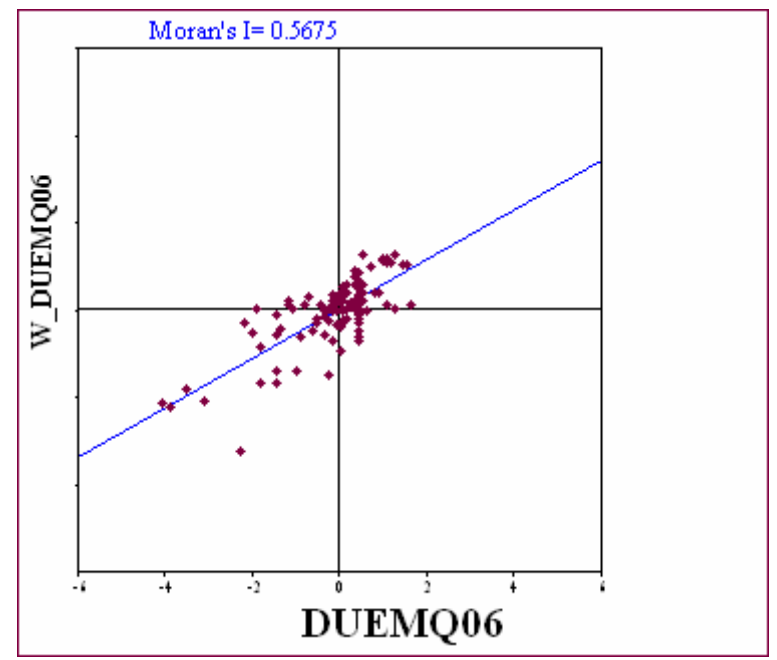


This implies that spatial autocorrelation might lead to new insights concerning the relationships between the dependent and the explaining variables but also in the influences between the neighbouring regions.

When comparing the LM test statistics for the regressions for each year, the LM lag test statistic is significant, respectively more significant while the LM error test statistic is not significant respectively less significant. This indicates substantial spatial autocorrelation in the regression, which is taken care of by the spatial lag model.

The OLS estimate and the spatial maximum likelihood estimate for the year 2004 are shown below:

OLS estimation

\begin{tabular}{|c|c|c|c|c|c|c|c|c|}
\hline \multicolumn{9}{|l|}{ REGRESSION } \\
\hline \multicolumn{9}{|c|}{$\begin{array}{l}\text { SUMMARY OF OUTPUT: ORDINARY LEAST SQUARES ESTIMATION } \\
\text { Data set }\end{array}$} \\
\hline \multicolumn{2}{|c|}{ Dependent Variable } & : & \multicolumn{2}{|c|}{ DUEMQO4 } & \multicolumn{3}{|c|}{ Number of Observations: } & 129 \\
\hline \multirow{2}{*}{\multicolumn{2}{|c|}{$\begin{array}{l}\text { Mean dependent var } \\
\text { S.D. dependent var }\end{array}$}} & : & \multicolumn{2}{|c|}{0.116512} & \multicolumn{2}{|c|}{ Number of Variables } & : & 7 \\
\hline & & : & \multicolumn{2}{|c|}{0.781659} & \multicolumn{2}{|c|}{ Degrees of Freedom } & : & 122 \\
\hline \multicolumn{2}{|l|}{ R-squared } & : & \multicolumn{2}{|c|}{0.220735} & \multicolumn{2}{|c|}{ F-statistic } & : & 5.75964 \\
\hline \multicolumn{2}{|c|}{ Adjusted R-squared } & & \multicolumn{2}{|c|}{0.182411} & \multicolumn{2}{|c|}{ Prob (F-statistic) } & \multicolumn{2}{|c|}{$: 2.63359 e-005$} \\
\hline \multicolumn{3}{|c|}{ Sum squared residual: } & \multicolumn{2}{|c|}{61.4199} & \multicolumn{2}{|c|}{ Log likelihood } & $:$ & -135.179 \\
\hline Sigma-square & & : & \multicolumn{2}{|c|}{0.503442} & \multicolumn{2}{|c|}{ Akaike info criterion } & $:$ & 284.358 \\
\hline \multirow{2}{*}{\multicolumn{2}{|c|}{$\begin{array}{l}\text { S.E. of regression } \\
\text { Sigma-square ML }\end{array}$}} & : & \multicolumn{2}{|c|}{0.709536} & \multicolumn{2}{|c|}{ Schwarz criterion } & $:$ & 304.377 \\
\hline & & : & \multicolumn{2}{|c|}{0.476123} & & & & \\
\hline \multicolumn{3}{|c|}{ S.E of regression ML: } & \multicolumn{4}{|c|}{0.690017} & & \\
\hline Variable & \multicolumn{3}{|c|}{ Coefficient } & \multicolumn{2}{|c|}{ Std. Error } & t-Statistic & & Probability \\
\hline CONSTANT & -0.07 & 769 & & & .1084369 & -0.7096639 & & 0.4792654 \\
\hline STD_POP03 & -0.005 & 588 & 37 & 0.00 & 8734344 & -0.6733691 & & 0.5019877 \\
\hline RAD_R03 & & .05 & 89 & & 2456792 & 4.276672 & & 0.0000379 \\
\hline HRST 04 & 0.004 & & 71 & 0.0 & 0541113 & 0.7545136 & & 0.4519954 \\
\hline LF_GRW0 4 & -0.2 & 261 & 51 & 0.0 & 09789919 & -2.673516 & & 0.0085339 \\
\hline UEMQO 4 & -0.002 & & 58 & & 0122013 & -0.1703637 & & 0.8650122 \\
\hline DLOG_GDP 03 & 0.0 & 037 & 33 & 0.0 & 4327244 & 0.8761537 & & 0.3826686 \\
\hline
\end{tabular}

REGRESSION DIAGNOSTICS

MULTICOLLINEARITY CONDITION NUMBER 7.058841

TEST ON NORMALITY OF ERRORS

$\begin{array}{lrcl}\text { TEST } & \text { DF } & \text { VALUE } & \text { PROB } \\ \text { Jarque-Bera } & 2 & 152.1158 & 0.0000000\end{array}$

DIAGNOSTICS FOR HETEROSKEDASTICITY

RANDOM COEFFICIENTS

TEST

$\begin{array}{ll}\text { Breusch-Pagan test } & 6 \\ \text { Koenker-Bassett test } & 6\end{array}$

SPECIFICATION ROBUST TEST

TEST DF

White 27

$\begin{array}{ll}\text { VALUE } & \text { PROB } \\ 94.02091 & 0.0000000 \\ 26.22184 & 0.0002024 \\ & \\ \text { VALUE } & \text { PROB } \\ 73.90321 & 0.0000031\end{array}$

DIAGNOSTICS FOR SPATIAL DEPENDENCE

\begin{tabular}{|c|c|c|c|c|}
\hline TEST & & $\mathrm{MI} / \mathrm{DF}$ & VALUE & PROB \\
\hline Moran's I (error) & & 0.144921 & 2.7694124 & 0.0056159 \\
\hline Lagrange Multiplier & $(\operatorname{lag})$ & 1 & 9.9823217 & 0.0015805 \\
\hline Robust LM (lag) & & 1 & 8.6695339 & 0.0032357 \\
\hline Lagrange Multiplier & (error) & 1 & 5.1837789 & 0.0227987 \\
\hline Robust LM (error) & & 1 & 3.8709912 & 0.0491275 \\
\hline Lagrange Multiplier & (SARMA) & 2 & 13.8533129 & 0.0009813 \\
\hline
\end{tabular}


Maximum likelihood spatial lag estimation:

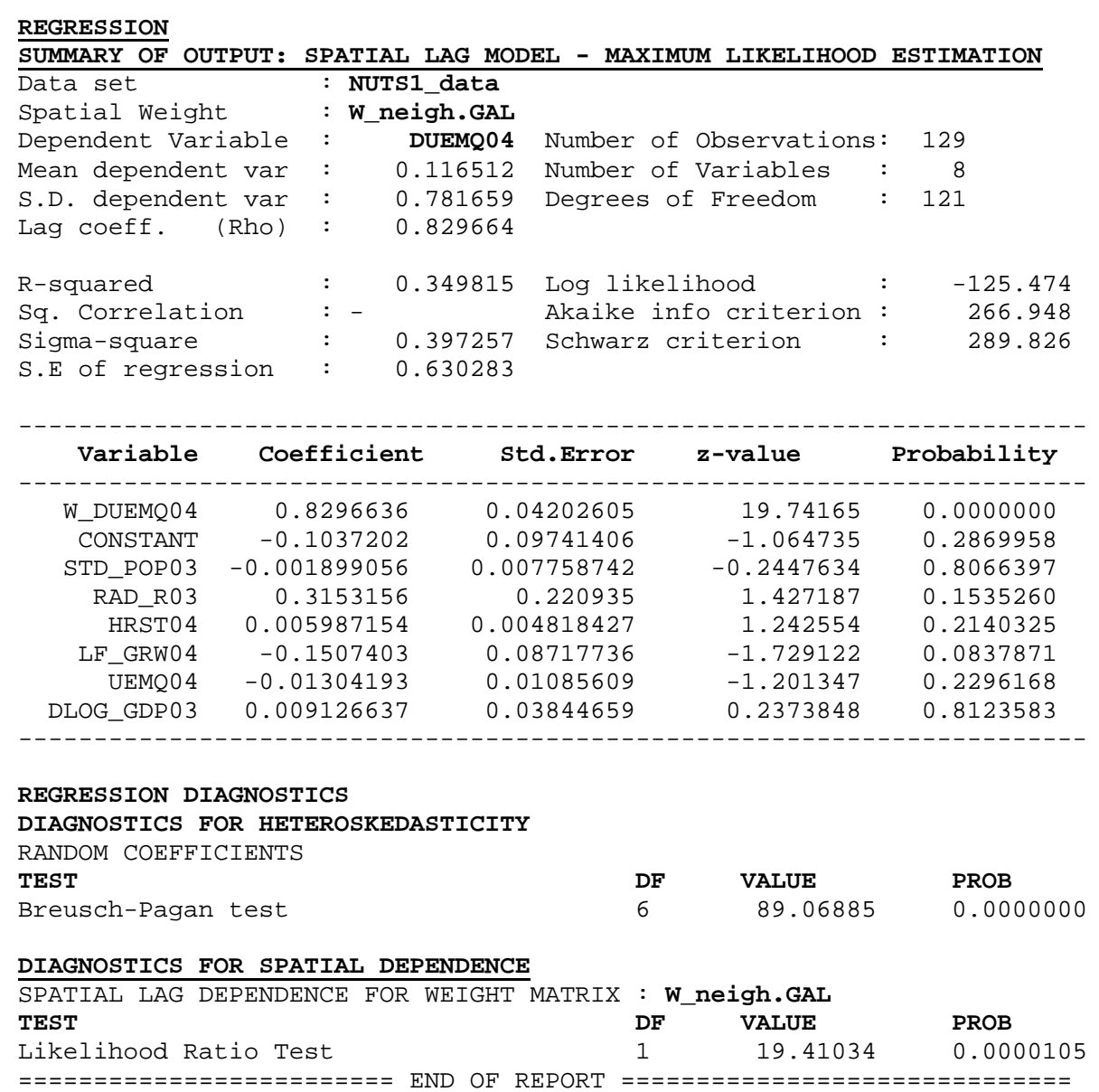

In the second estimation no coefficient except the spatial lag coefficient is significant anymore.

One also recognizes that the estimates obtained by OLS are biased, e.g. for the variable research and development per person the hypothesis test of $\mathrm{H}_{0}$ : $\mathrm{b}_{\mathrm{OLS}}=\mathrm{b}_{\text {lag }}$ results in a $\mathrm{t}$-value of 2.99 which leads to the rejection of the $\mathrm{H}_{0}$. This also means that the results discussed above, which were obtained by the panel estimation, are biased.

Repeating the regressions for each year separately since an estimation over the whole period under observation is not possible when taking into account spatial effects, shows that hardly any of the variables turn out to be significant. In the year 2003 the coefficient of the lagged research and development expenditure and the level of the unemployment turn out to be significant, in the year 2002 no variable is significant and in the year 2001 the coefficient of the percentage of the labour force in science and technology is significant.

Summarizing these results one can say that the influence of intangible assets on the change in the unemployment ratio seems small or nonexistent at all, but there is a substantial influence 
of the change in the unemployment ratio in the neighbouring regions on the change in the unemployment ratio in the considered region.

This substantial influence is feasible since one can imagine that if one region manages to lower their unemployment ratio, workers from other regions will either move there or will be able to find work there and thus lower the unemployment ratio in their region.

\subsection{Patents as an indicator of innovation}

\subsubsection{Descriptive statistics concerning the total number and different sectors of patents}

Patents are one of the best indicators for the innovation abilities of a country and as such earn special attention when analysing the effect of intangible assets on the growth rate of the GDP.

Table 5 - Number of patents per one million inhabitants (2002)

\begin{tabular}{|ll|}
\multicolumn{1}{c}{ Top Ten } \\
\hline nl4 Zuid-Nederland & 659,50 \\
del Baden-Württemberg & 602,07 \\
de2 Bayern & 466,91 \\
de7 Hessen & 319,51 \\
deb Rheinland-Pfalz & 309,73 \\
fil Manner-Suomi & 308,10 \\
frl l̂le de France & 296,18 \\
& \\
dea Nordrhein-Westfalen & 267,18 \\
de6 Hamburg & 232,98 \\
fr7 Centre-Est & 231,64 \\
\hline
\end{tabular}

\section{Bottom Ten}

\begin{tabular}{|lr|}
\hline lv0 Lettland & 5,53 \\
p15 Poludniowo-Zachodni & 4,91 \\
pt1 Continente (PT) & 4,81 \\
gr1 Voreia Ellada & 4,14 \\
p12 Poludniowy & 4,02 \\
gr2 Kentriki Ellada & 3,85 \\
fr9 Französische & \\
Departemente (FR) & \\
pl6 Pólnocny & 3,61 \\
pl4 Pólnocno-Zachodni & 3,22 \\
lt0 Litauen & 2,78 \\
\hline
\end{tabular}

Figure 13 - Number of registered patents per one million inhabitants

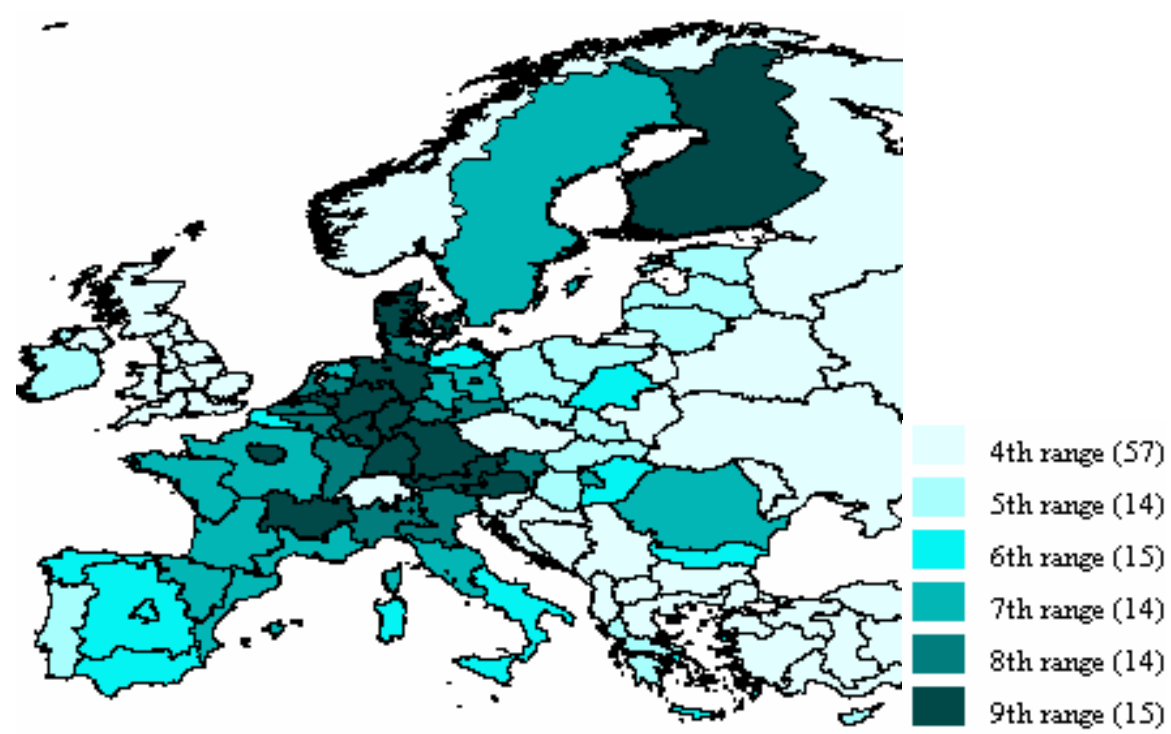


When considering the number of patents per one million inhabitants there is again a big difference between East and West Europe recognisable.

Testing on mean equality results consequently in the rejection of the null hypothesis. The mean for Western Europe is 100.82, while it is only 5.67 for Eastern Europe.

The growth rate of the patents is expected to influence the growth rate of the GDP in the future, thus the regression of the growth rate of the GDP on the lagged value of the growth rate of the patents is supposed to result in a positive significant coefficient. The estimated coefficient is indeed positive (value of 0.0128 ) but only significant on the $10 \%$ confidence level.

Dividing the sample in the Eastern and Western part of Europe the estimate of the coefficient remains pretty much unchanged, while the standard deviation varies. In the sample of the Eastern European countries the variance of the estimation is greater. This might be due to a smaller sample size, but also because of inherent greater variance. Testing the series of the growth rate of the patents on variance equality between Eastern and Western Europe, the latter is confirmed. In the sample of the Eastern European countries the standard deviation is 41.08 as compared to 24.67 for the Western European countries, which is a significant difference.

The coefficient for Western Europe becomes more significant, since the standard error is reduced.

When analysing the effect for different countries it is remarkable that the effect is not significantly bigger (on the $1 \%$ confidence level) for countries like Germany or France, which are among the countries having the highest number of patents than for the sample in general.

$\begin{array}{llll}\mathrm{b} & \mathrm{se} & & \mathrm{t} \text {-value } \\ 0.012818 & 0.007467 & \text { total } & \\ 0.058523 & 0.022174 & \mathrm{FR} & 2.061198 \\ 0.024815 & 0.010068 & \mathrm{DE} & 1.191597\end{array}$

The same can be said for the countries like Greece and Poland which have a very low number of patents.

In general, the size of the effect of the growth rate of the patents on the GDP does not seem to depend on the absolute number of patents, but is constant among the sample.

As can be expected from the result mentioned above for the standard deviation, the variance of the residual is not constant among the sample, i.e. heteroscedasticity is present. 
This is again due to differences in between the regions rather than differences in the regions itself, e.g. the variance for the regression done for only Germany or only Spain is homoscedastic.

This implies that even though the estimated coefficient is not significantly different for the regions estimation over all the regions is not correct, since the standard errors will be calculated incorrectly.

When trying to explain the growth rate of the GDP spatial autocorrelation was always present, even though not in the substantial form. This result holds true when regressing the growth rate of the GDP on the lagged growth rate of the number of registered patents.

A Moran's I z-value of 0.4389 indicates significant spatial autocorrelation but the respective LM statistics point to non substantive autocorrelation, i.e. an influence of the regions in between themselves that is only transmitted over the error term.

The heteroscedasticity that was present in the panel regression disappears when using the spatial error model.

This means that there is no new information to be drawn out of the spatial regression. The estimates obtained above are unbiased and the calculated standard errors rather conservative.

Table 6 - Number of patents in the hightechnology sector per one million inhabitants (2002)

\begin{tabular}{|ll|}
\multicolumn{1}{c}{ Top Ten } \\
\hline nl4 Zuid-Nederland \\
fil Manner-Suomi & 241,00 \\
& 135,92 \\
de2 Bayern & 109,54 \\
frl Ille de France & 76,91 \\
del Baden-Württemberg & 71,01 \\
de3 Berlin & 56,27 \\
fr7 Centre-Est & 45,86 \\
dk0 Dänemark & 39,17 \\
at 1 Ostösterreich & 38,30 \\
be2 Vlaams Gewest & 37,21 \\
\hline
\end{tabular}

\begin{tabular}{|ll|}
\multicolumn{1}{c}{ Bottom Ten } \\
\hline cz0 Czech Republic \\
pl4 Pólnocno-Zachodni & 0,75 \\
& 0,67 \\
pl2 Poludniowy & 0,54 \\
hu3 Alföld és Észak & 0,47 \\
es4 Centro (ES) & 0,46 \\
pt1 Continente (PT) & 0,34 \\
pl6 Pólnocny & 0,34 \\
gr2 Kentriki Ellada & 0,22 \\
pl3 Wschodni & 0,04 \\
es7 Canarias (ES) & 0,01 \\
\hline
\end{tabular}

The difference between East and West is again easily remarkable and significant. The respective means of the variables are 17.75 and 0.80 .

Patents in the high technology sector do not lead to a significant higher influence of the number of patents on the GDP. In a regression with the interaction variable of the percentage of the high technology patents with the growth rate of patents, the coefficient turns out to be insignificant.

The rankings for the patents divided into different sectors are included at the end. 
There are not many special remarks to be made about the distribution since it basically reflects the general distribution of patents in Europe.

One interesting note is that the different regions of Germany are extremely well placed in all the sectors of the economy, when considering patents.

Otherwise the distribution of the number of patents reflects the economic situation in many cases. In France for example only the region Ile de France and sometimes the region Centre Est can be found in the top ten, which reflects the strong centralisation.

While the region Nord Est of Italy can in certain sectors be found in the top ten, the region Isole, which is in the south of the country, appears in the bottom ten for certain sectors, reflecting the strong north-south divide.

In the sector textile and paper the East European countries do not appear in the rankings, which is due to the lack of data for this sector and this year.

In all these rankings it has to be taken into account that the data was not available for all the regions in the same quality, e.g. there was no data available for the year 2002 for the UK.

Analysing whether patents in the different sections have a significant different influence on the GDP, a regression of the growth rate of the GDP on the relative portions of the patents in the respective sector can be done.

This might be reasonable because certain key sectors of the European economy such as chemistry, with the fast growing biotechnology companies, or engineering might add more to the GDP than e.g. textile or agriculture.

The regression results are however not significant. With the relative portion of patents in the electrical engineering sector as the reference, all the other variables turn out to be insignificant. 
Total panel (unbalanced) observations: 486

\begin{tabular}{lllll}
\hline \hline Variable & Coefficient & Std. Error & t-Statistic & Prob. \\
\hline \hline C & 1.638434 & 5.596558 & 0.292757 & 0.7699 \\
PATA & 0.050782 & 0.070987 & 0.715377 & 0.4748 \\
PATB & 0.052466 & 0.072375 & 0.724920 & 0.4689 \\
PATC & 0.086305 & 0.071869 & 1.200869 & 0.2305 \\
PATD & 0.075390 & 0.199739 & 0.377440 & 0.7060 \\
PATE & -0.092711 & 0.084800 & -1.093287 & 0.2749 \\
PATF & -0.055276 & 0.082625 & -0.668989 & 0.5039 \\
PATG & 0.017878 & 0.090709 & 0.197089 & 0.8439 \\
\hline \hline & Effects Specification & & \\
& \multicolumn{5}{l}{$\begin{array}{l} \\
\text { Cross-section fixed (dummy variables) }\end{array}$} & & & \\
\hline \hline & & & & \\
R-squared & 0.357015 & Mean dependent var & 4.486543 \\
Adjusted R-squared & 0.230005 & S.D. dependent var & 4.872848 \\
S.E. of regression & 4.275893 & Akaike info criterion & 5.894875 \\
Sum squared resid & 7404.721 & Schwarz criterion & 6.592576 \\
Log likelihood & -1351.455 & F-statistic & 2.810928 \\
Durbin-Watson stat & 1.589502 & Prob(F-statistic) & 0.000000 \\
\hline \hline
\end{tabular}

\subsubsection{Determinants of the growth rate of patents}

One of the main determinants of the number of patents is expected to be the amount of expenditure for research and development.

Since research and development and the registration of patents is not a simultaneous process, i.e. the money being spent today will probably not lead to a registration of a patent in the same year, it is advisable to consider the lagged variable of research and development expenditure. The power of explanation, i.e. the $\mathrm{R}^{2}$ is highest for the second lag when considering the whole panel. This implies that it takes about two years for the money spent in research and development to have an impact on the number of patents registered

In order to avoid problems with nonstationarity the growth rates of the variables are considered. 
The coefficient of research and development shows the expected sign is however insignificant.

This might be due to differences in the efficiency of research and development expenditure in the different countries, which leads to a greater variance in the sample and consequently to an insignificant coefficient.

Repeating the regression for some countries, affirms this assumption.

While the coefficient for research and development for Germany has the highest power of explanation in the first lag and a highly significant coefficient of 2.29 (p-value of 0.003), the coefficient for France (without the oversea departments) takes on a value of only 0.22 in the second lag, which is insignificant.

The same can be seen when taking examples for countries with a very low number of patents like Spain and Greece. For Spain the first lag of the research and development expenditure delivers a better fit while for Greece it is the second lag. Both of the coefficients however turn out to be insignificant, with the coefficient for Spain showing the wrong sign in addition.

This indicates that a panel regression which assumes an equal effect of research and development expenditure for all the countries in the panel is not appropriate.

Taking into account the results above one would clearly expect heteroscedasticity to be present.

The test whether the variance of the four countries mentioned above as an example is equal, shows that they are clearly not. 


\begin{tabular}{l|llll}
\hline \hline & & & Mean Abs. & Mean Abs. \\
CLASS & Count & Std. Dev. & Mean Diff. & Median Diff. \\
\hline 0 & 72 & 24.64802 & 15.59430 & 15.59430 \\
1 & 32 & 12.75192 & 8.552571 & 8.552571 \\
2 & 24 & 7.289402 & 5.620790 & 5.604395 \\
3 & 16 & 33.25531 & 20.03689 & 19.47804 \\
4 & 9 & 32.91692 & 26.88610 & 26.35159 \\
\hline All & 153 & 22.16182 & 13.68585 & 13.59340 \\
\hline \hline
\end{tabular}

Bartlett weighted standard deviation: 22.45931

Where class 1 is Germany, class 2 France, class 3 Spain and class 4 Greece.

When considering the residuals of the regressions done for one region at a time, the heteroscedasticity vanishes.

In order to gain reliable results for this regression about the size as well as the accuracy of this effect one thus has to regress each region separately.

In the growth rate of the patents there is no significant spatial autocorrelation present. The Moran*s I z-value is only 0.13 , which is not significant. This means that the growth rate of the patents does not influence the growth rate of the patents in the neighboring regions.

Consequently spatial regression does not have to be used, since the effects would turn out to be insignificant.

In order to be able to make more accurate statements a measure for the efficiency of research and development would be useful. One possible measure might be calculating the amount of money that has to be spent in order to register one patent, i.e. the total amount of research and development expenditure divided by the total number of patents. 
Table 7 - Research and development expenditure divided by the total number of patents (2002)

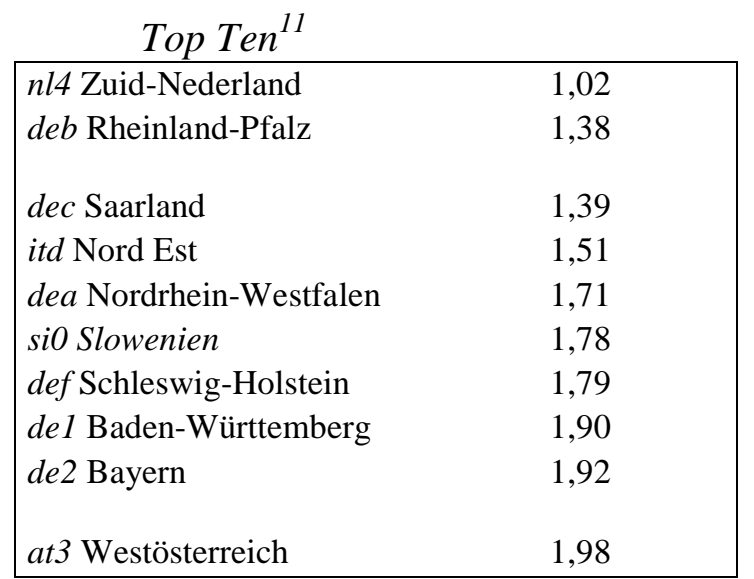

\begin{tabular}{|c|c|}
\hline Bottom Ten & \\
\hline es3 Comunidad de Madrid & 9,97 \\
\hline ltO Litauen & 10,32 \\
\hline itg Isole (IT) & 10,33 \\
\hline es7 Canarias (ES) & 10,85 \\
\hline es4 Centro (ES) & 11,41 \\
\hline gr2 Kentriki Ellada & 11,54 \\
\hline de 5 Bremen & 13,25 \\
\hline ptl Continente $(P T)$ & 21,28 \\
\hline fr9 Französische & 58,39 \\
\hline Departemente (FR) & \\
\hline grl Voreia Ellada & 98,23 \\
\hline
\end{tabular}

Looking at the regression results above for France and Germany one would expect German research and development to be more efficient than French expenditure. This is confirmed when looking at the ranking of the newly created measure. While the most active regions in Germany, Bavaria and Baden Württemberg, are among the top ten, Ile de France is ranking 43 out of 73 regions for which data is available.

The measures for Greece and Spain indicate a low efficiency in these countries, which explains the insignificant coefficient of research and development expenditure.

One would expect that the efficiency of research and development has a positive impact on the growth rate of the patents, i.e. that the coefficient of the measure in a regression is negative, since a low value of research and development divided by patents indicates efficiency.

This can be confirmed, since the coefficient in the regression takes on a negative, highly significant value. The direction of the relationship is however not obvious. It might be that a high efficiency leads to a high number of registered patents, but it might also be possible that a high number of patents leads to a high efficiency because of learning effects or economies of scale.

Another measure that might be created in order to explain the efficiency of research and development is the division of the number of human resources in science and technology divided by the number of patents. This might also be taken as an indicator of the level of education of the workers employed in that sector, since well educated workers are expected to register a higher number of patents.

\footnotetext{
${ }^{11}$ The data for the Czech Republic indicated a value of 0.07 , which is clearly not reliable. This led to the exclusion of this country.
} 
Table 8 - Human resources in science and technology divided by the total number of patents (2002)

\begin{tabular}{|c|c|}
\hline Top Ten & \\
\hline nl4 Zuid-Nederland & 0,33 \\
\hline del Baden-Württemberg & \\
\hline de2 Bayern & $\begin{array}{l}0,50 \\
0.46\end{array}$ \\
\hline deb Rheinland-Pfalz & 0,66 \\
\hline de7 Hessen & 0,72 \\
\hline dea Nordrhein-Westfalen & 0,73 \\
\hline at3 Westösterreich & 0,76 \\
\hline$u k h$ Eastern & 0,78 \\
\hline at2 Südösterreich & 0,79 \\
\hline fil Manner-Suomi & 0,79 \\
\hline
\end{tabular}

\begin{tabular}{|l}
\multicolumn{1}{l}{ Bottom Ten } \\
\hline pl5 Poludniowo-Zachodni \\
cy0 Zypern \\
pl2 Poludniowy
\end{tabular}

The ranking is similar to that above and calculating the correlation coefficient between these two variables shows that there is high degree of correlation (cor=0.81), which means that this variable should not be added in the regression, since the presence of multicollinearity would result in estimation problems.

This indicates that the explanation done by those two variables would be similar, which means that an inclusion of this variable would not lead to new information that can be drawn out of the regression.

\section{Conclusion}

Intangible assets do have a significant influence on the growth rate of the GDP. The regression of the growth rate of the GDP on those factors has an $\mathrm{R}^{2}$ of 0.57 , this means that more than half of the variation of the growth rate of the GDP in Europe can be explained by those factors. For Western Europe the power of explanation is even higher with an $\mathrm{R}^{2}$ of 0.75 .

On the other hand the change in the unemployment ratio does not seem to be influenced by intangible assets as much as was expected.

Spill over effects and other spatial effects are present but when considering the growth rate are not yet substantial. But the data indicate that this fact that might change in the future as the ties between the countries become closer. A continued observation will be necessary to draw any certain conclusions.

The spatial effects for the unemployment ratio however are already highly significant and substantial probably a direct result of the Schengen agreement and the consequent high mobility of the labour force.

Another fact that can be confirmed is that there are still big differences between the countries, especially between East and West Europe. A panel estimation generalizing the effects of the 
explaining variables over these two regions is mostly not appropriate. But the differences between the two regions are closing fast. Again a continued observation of the development is necessary.

In general the time period under observation was relatively small and especially since some major changes like the entry of the new member states have taken place so recently, the future development is hard to predict and will have to be monitored carefully. 


\section{References}

Anselin, L.(2005): Exploring Spatial Data with GeoDa: A Workbook, 2005

Anselin, L. (1992): Spatial Data Analysis with GIS: An introduction to application in the social sciences, Technical Report, August 1992

Becker, G. S. (1993): Human Capital: A Theoretical and Empirical Analysis, with Special Reference to Education. Chicago, University of Chicago Press.

Barro, R. J., Sala-i-Martin, Xavier (1995, 2003 2nd ed.); Economic Growth. New York: McGraw-Hill.

Brynjolfsson, E., Hitt L. M., Yang S. (2002): Intangible Assets: Computers and Organizational Capital,. eBusiness@MIT WP 138, MIT, Cambridge Massacusetts.

Burt, R. (1992): Structural holes: The social structure of competition, Harvard University Press, Cambridge, Massachsetts.

Corrado, C., Hulten, C., Sichel, D. (2006): Intangible Capital and Economic Growth, Finance and Economics Discussion Series 2006-24, Federal Reserve Board, Washington D.C.

Dakhli, M., de Clercq, D. (2004) : Human capital, social capital, and innovation: a multicountry study. in: Entrepreneurship and Regional Development, 16, 107-128.

Eckey, H.-F., Dreger, C., Türck, M. (2006), European Regional Convergence in a Human Capital Augmented Solow Model,. DIW Discussion Paper 631, German Institute for Economic research, Berlin, 2006.

Erber, G. (1994): Verdoorn's or Okun's Law?, Employment and Growth Experiences in OECD Countries, 1960-1993. DIW Discussion Paper 98, German Institute for Economic research, Berlin, 1994.

Erber, G., Sayed-Ahmed, A. (2005): Offshore Outsourcing, A global shift in the present IT industry, in: Intereconomics, Review of European Economic Policy, 50, issue 2, 100112.

Erber, G. (2003): Okun's Law and the Employment Crisis in Europe, in: New Developments in Growth Theory and Growth Policy, eds. H. Hagemann, S. Seiter, Routledge, London, 175-186.

Erber, G., Hagemann, H. (2002): Growth, Structural Change, and Employment, in: Frontiers of Economics, Ed. Klaus F. Zimmermann, Springer-Verlag, Berlin - Heidelberg New York, 269-310.

Fingleton, B., López-Bazo, E. (2006): Empirical growth model with spatial effects, in: Journal of Regional Science, June 2006

Friedman, T. 1. (2005): The World Is Flat: A Brief History of the Twenty-First Century, Farrar, Strauss \& Giroux, New York, 2005.

Funke, M., Niebuhr, A. (2005): Regional Geographic Research and Development Spillovers and Economic Growth: Evidence from West Germany, Regional Studies, 39.1, 143153.

Jones, Ch. I. (2005): Growth and Ideas, in: P. Aghion and S. Durlauf (eds.) Handbook of Economic Growth (Elsevier, 2005), Volume 1B, 1063-1111.

Jorgenson, D: W., Landefeld, S. J., Nordhaus, W: D: eds. (2006): A New Architecture for the U.S. National Accounts, Chicago University Press, 2006. 
Kosfeld, R., Dreger, C. (2006), Thresholds for Employment and Unemployment: A Spatial Analysis of German Regional Labour Markets, 1992-2000. in: Papers in Regional Science 85 (2006), 4, 523-542.

Kosfeld, R., Eckey, H.-F., Dreger, C. (2006), Regional Productivity and Income Convergence in the Unified Germany, 1992 - 2000. in: Regional Studies 40, 7, 755-767

Krugman, P., Venables, A. J. (1995): Globalization and the Inequality of Nations: in: Quarterly Journal of Economics, 110, 857-880.

Krugman, P. (1991): Increasing Returns and Economic Geography, in: The Journal of Political Economy, 99, 483-499.

Mankiw, N.G., Romer, D., and Weil, D.N. (1992): A contribution to the empirics of economic growth. in: Quarterly Journal of Economics, 107(2), 407-437.

OECD (2007): Compendium of Patent Statistics -2007, OECD, Paris.

OECD (2005): Offshoring and Employment, Trends and Impacts, OECD, Paris.

Rosen, S. (1987): Human capital, in: The New Palgrave: A Dictionary of Economics, vol. 2, 681-90.

Venables, A: J. (2006): Shifts in economic geography and their causes, in: CentrePiece, Winter 2006/2007, 12-19.

von Thadden, E. L. (1990): On the Efficiency of the Market for Corporate Control, in: Kyklos, 43 , 


\section{Appendix}

\section{Ranking of patents}

Registration of patents at the EPA classified by IPK sections on regional basis (year2002) Section A - Daily necessities, per one million inhabitants

$\begin{array}{ll}\text { de6 Hamburg } & 71,244 \\ d k 0 \text { Dänemark } & 55,787 \\ \text { del Baden-Württemberg } & 51,2906 \\ \text { def Schleswig-Holstein } & 50,2151 \\ \text { frl } \text { Île de France } & 49,9046 \\ \text { nl4 Zuid-Nederland } & 47,3892 \\ \text { de7 Hessen } & 46,5785 \\ \text { deb Rheinland-Pfalz } & 44,8815 \\ \text { de2 Bayern } & 42,5565 \\ i t d \text { Nord Est } & 36,895 \\ \text { fr7 Centre-Est } & 36,4781\end{array}$

\begin{tabular}{ll}
\multicolumn{2}{c}{ Bottom Ten } \\
gr2 Kentriki Ellada & 1,2788 \\
sk 0 Slowakei & 1,111 \\
pl2 Poludniowy & 0,9614 \\
grl Voreia Ellada & 0,9563 \\
ptl Continente $(P T)$ & 0,9347 \\
hu2 Dunántúl & 0,7813 \\
pl4 Pólnocno-Zachodni & 0,7276 \\
pl6 Pólnocny & 0,5893 \\
lto Litauen & 0,5754 \\
pl3 Wschodni & 0,1836 \\
pt3 Região Autónoma da Madeira0,1747 \\
(PT)
\end{tabular}

Registration of patents at the EPA classified by IPK sections on regional basis (year2002) Section B - Operating technique, transport, per one million inhabitants Top Ten

del Baden-Württemberg

de2 Bayern

de 7 Hessen

94,4678

78,8561

deb Rheinland-Pfalz

at3 Westösterreich

71,7067

60,28

58,694

52,1597

itd Nord Est

51,9436

49,8685

48,9842

47,9874

\section{Bottom Ten}

$\begin{array}{ll}\text { itg Isole (IT) } & 1,0939 \\ \text { pl5 Poludniowo-Zachodni } & 0,7673 \\ \text { eeO Estland } & 0,7346 \\ \text { pl2 Poludniowy } & 0,541 \\ \text { grl Voreia Ellada } & 0,5369 \\ \text { pl6 Pólnocny } & 0,4983 \\ \text { gr2 Kentriki Ellada } & 0,462 \\ \text { lvO Lettland } & 0,4263 \\ \text { pl4 Pólnocno-Zachodni } & 0,3523 \\ \text { pl3 Wschodni } & 0,2153 \\ \text { lt } 0 \text { Litauen } & 0,1439\end{array}$

Registration of patents at the EPA classified by IPK sections on regional basis (year2002) Section C - Chemistry, metallurgy, per one million inhabitants

\section{Top Ten}

deb Rheinland-Pfalz

de 7 Hessen

78,8452

dea Nordrhein-Westfalen

59,5109

49,0363

del Baden-Württemberg

de $\quad$ Bruxelles-51,4487

Capitale/Brussels Hoofdstedelijk

Gewest

de6 Hamburg

39,3519

be3 Région Wallonne

de3 Berlin

43,6794

nl4 Zuid-Nederland

39,5905

50,9104

$d k 0$ Dänemark

39,5815

fr7 Centre-Est

39,9039

\section{Bottom Ten}

$\begin{array}{lr}\text { ptl Continente (PT) } & 0,6635 \\ \text { pl6 Pólnocny } & 0,5547 \\ \text { grl Voreia Ellada } & 0,5184 \\ \text { pl3 Wschodni } & 0,5162 \\ \text { lvO Lettland } & 0,4831\end{array}$

pl4 Pólnocno-Zachodni $\quad 0,3846$

cy0 Zypern $\quad 0,3543$

lto Litauen $\quad 0,2877$

pt3 Região Autónoma da Madeira0,1456 (PT)

fr9 Französische überseeische0,098

Departemente (FR)

es7 Canarias (ES) $\quad 0,0572$ 
Registration of patents at the EPA classified by IPK sections on regional basis (year2002) Section D - Texitles, paper, per one million inhabitants

\section{Top Ten}

fil Manner-Suomi

del Baden-Württemberg

at3 Westösterreich

at2 Südösterreich

be2 Vlaams Gewest

fr7 Centre-Est

dea Nordrhein-Westfalen

de2 Bayern

itc Nord Ovest

deb Rheinland-Pfalz

atl Ostösterreich
21,3134

18,6796

10,2937

9,1838

8,1305

7,9895

7,0183

6,9906

6,1361

5,8053

5,0382

\section{Bottom Ten}

$\begin{array}{lr}\text { itf Sud (IT) } & 0,275 \\ \text { gr3 Attiki } & 0,2561 \\ \text { pt3 Região Autónoma da Madeira0,1456 } \\ \text { (PT) } & \\ \text { es6 Sur } & 0,1243 \\ \text { es3 Comunidad de Madrid } & 0,0338 \\ \text { de8 Mecklenburg-Vorpommern } & 0,0138 \\ \text { itg Isole (IT) } & 0,0103 \\ \text { es } 1 \text { Noroeste } & 0,0085 \\ \text { es7 Canarias (ES) } & 0,0072 \\ \text { es4 Centro (ES) } & 0,0066 \\ \text { fr9 Französische } & \text { überseeische0,0002 } \\ \text { Departemente (FR) } & \end{array}$

Registration of patents at the EPA classified by IPK sections on regional basis (year2002)

Section E - Building industry; mining, per one million inhabitants

\section{Top Ten}

at3 Westösterreich

del Baden-Württemberg

dea Nordrhein-Westfalen

de2 Bayern

at2 Südösterreich

atl Ostösterreich

dec Saarland

deb Rheinland-Pfalz

$d k 0$ Dänemark

itd Nord Est

fr4 Est

\section{Bottom Ten}

$\begin{array}{lr}\text { itg Isole (IT) } & 0,561 \\ \text { pl6 Pólnocny } & 0,555 \\ \text { itf Sud (IT) } & 0,537 \\ \text { pl4 Pólnocno-Zachodni } & 0,519 \\ \text { gr2 Kentriki Ellada } & 0,446 \\ \text { pl2 Poludniowy } & 0,406 \\ \text { hu2 Dunántúl } & 0,401 \\ \text { sk0 Slowakei } & 0,372 \\ \text { pl3 Wschodni } & 0,307 \\ \text { pl5 Poludniowo-Zachodni } & 0,204 \\ \text { pt3 Região Autónoma da Madeira0,146 }\end{array}$

(PT)

Registration of patents at the EPA classified by IPK sections on regional basis (year2002) Section F - Engineering; light; heating; arms; explosions, per one million inhabitants

$$
\text { Top Ten }
$$

del Baden-Württemberg

de2 Bayern

115,387

68,4599

31,4407

31,072

30,8766

30,806

28,2193

27,6042

26,0857

22,9122

21,546

\section{Bottom Ten}

$\begin{array}{lr}\text { es6 Sur } & 0,4071 \\ \text { pl5 Poludniowo-Zachodni } & 0,4046 \\ \text { es4 Centro (ES) } & 0,3826 \\ \text { grl Voreia Ellada } & 0,3595 \\ \text { hu2 Dunántúl } & 0,3208 \\ \text { pt1 Continente (PT) } & 0,3045 \\ \text { pl4 Pólnocno-Zachodni } & 0,2656 \\ \text { gr4 Nisia Aigaiou, Kriti } & 0,2031 \\ \text { pl3 Wschodni } & 0,1566 \\ \text { pl2 Poludniowy } & 0,106 \\ \text { fr9 Französische überseeische } 0,0014 \\ \text { Departemente (FR) }\end{array}$

Registration of patents at the EPA classified by IPK sections on regional basis (year2002) Section G - Physics, per one million inhabitants

\section{Top Ten}

nl4 Zuid-Nederland

del Baden-Württemberg

de2 Bayern

259,364

111,245

85,8165

58,3841

\section{Bottom Ten}

es4 Centro (ES) $\quad 0,607$

pl5 Poludniowo-Zachodni $\quad 0,601$

hu2 Dunántúl $\quad 0,582$

sk 0 Slowakei $\quad 0,496$ 


\begin{tabular}{|c|c|}
\hline fil Manner-Suomi & 52,8949 \\
\hline fr7 Centre-Est & 40,9173 \\
\hline de3 Berlin & 39,6055 \\
\hline de6 Hamburg & 37,764 \\
\hline de7 Hessen & 34,5988 \\
\hline dea Nordrhein-Westfalen & 33,1874 \\
\hline$d k 0$ Dänemark & 30,5742 \\
\hline \multirow{2}{*}{\multicolumn{2}{|c|}{$\begin{array}{l}\text { Registration of patents at the EPA cl } \\
\text { Section } \mathrm{H}-\text { Electrical engineering }\end{array}$}} \\
\hline & \\
\hline \multicolumn{2}{|c|}{ Top Ten } \\
\hline nl4 Zuid-Nederland & 231,887 \\
\hline fil Manner-Suomi & 120,011 \\
\hline de2 Bayern & 112,84 \\
\hline de1 Baden-Württemberg & 81,7777 \\
\hline$f r l$ Île de France & 64,7248 \\
\hline de3 Berlin & 48,825 \\
\hline fr7 Centre-Est & 40,621 \\
\hline$d e 7$ Hessen & 36,830 \\
\hline dea Nor & 36,3731 \\
\hline & 34,216 \\
\hline atl Ostösterreich & 33,56 \\
\hline
\end{tabular}

\begin{tabular}{|c|c|}
\hline $13 \mathrm{~W}$ & 0,36 \\
\hline r4 Nisia Aigaiou, Krit & 0,3 \\
\hline ptl Continente (PT) & \\
\hline iki Ellada & 0,28 \\
\hline $\begin{array}{l}f r 9 \text { Französische üb } \\
\text { Departemente (FR) }\end{array}$ & iberseeische 0,19 \\
\hline 6 Pólnocny & 0 , \\
\hline 7 Canarias $(\mathrm{E}$ & \\
\hline
\end{tabular}

Registration of patents at the EPA classified by IPK sections on regional basis (year2002)

Top Ten

nl4 Zuid-Nederland

31,887

20,011

12,842

81,7777

48,8258

40,621

6,3731

33,5641

\section{Bottom Ten}

ptl Continente (PT)

grl Voreia Ellada $\quad 0,3976$

sk0 Slowakei $\quad 0,3718$

pl2 Poludniowy $\quad 0,329$

hu3 Alföld és Észak $\quad 0,321$

pl4 Pólnocno-Zachodni $\quad 0,3113$

es4 Centro (ES) $\quad 0,2028$

pt3 Região Autónoma da0,1456

Madeira (PT)

gr2 Kentriki Ellada $\quad 0,106$

pl3 Wschodni $\quad 0,0187$

es7 Canarias (ES) $\quad 0,0144$ 


\section{NUTS 1 regions}

\section{Complete list}

bel Région de Bruxelles-Capitale/Brussels Hoofdstedelijk Gewest

be2 Vlaams Gewest

be3 Région Wallonne

bg3 Severna i iztochna Bulgaria

bg4 Yugozapadna i yuzhna centralna Bulgaria

czO Czech Republic

$d k 0$ Dänemark

del Baden-Württemberg

de2 Bayern

de3 Berlin

de4 Brandenburg

de5 Bremen

de6 Hamburg

de 7 Hessen

de8 Mecklenburg-Vorpommern

de 9 Niedersachsen

dea Nordrhein-Westfalen

deb Rheinland-Pfalz

dec Saarland

ded Sachsen

dee Sachsen-Anhalt

def Schleswig-Holstein

deg Thüringen

ee 0 Estland

ie0 Irland

grl Voreia Ellada

gr2 Kentriki Ellada

gr3 Attiki

gr4 Nisia Aigaiou, Kriti

es1 Noroeste

es 2 Noreste

es 3 Comunidad de Madrid

es 4 Centro (ES)

es5 Este

es6 Sur

es7 Canarias (ES)

frl Île de France

fr2 Bassin Parisien

fr3 Nord - Pas-de-Calais

fr4 Est

fr5 Ouest

fr6 Sud-Ouest

fr 7 Centre-Est

fr8 Méditerranée

fr9 Französische überseeische Departemente (FR)

itc Nord Ovest

itd Nord Est

ite Centro (IT)

itf Sud (IT) 
itg Isole (IT)

cy0 Zypern

lv0 Lettland

ltO Litauen

lu0 Luxemburg (Grand-Duché)

hul Közép-Magyarország

hu2 Dunántúl

hu3 Alföld és Észak

mt0 Malta

nll Noord-Nederland

nl2 Oost-Nederland

$n l 3$ West-Nederland

nl4 Zuid-Nederland

atl Ostösterreich

at2 Südösterreich

at3 Westösterreich

pll Centralny

$p l 2$ Poludniowy

pl3 Wschodni

pl4 Pólnocno-Zachodni

pl5 Poludniowo-Zachodni

pl6 Pólnocny

ptl Continente (PT)

pt2 Região Autónoma dos Açores (PT)

pt3 Região Autónoma da Madeira (PT)

ro1 Macroregiunea unu

ro2 Macroregiunea doi

ro3 Macroregiunea trei

ro4 Macroregiunea patru

sio Slowenien

sk0 Slowakei

fil Manner-Suomi

fi2 Åland

se1 Östra Sverige

se2 Södra Sverige

se3 Norra Sverige

$u k c$ North East (ENGLAND)

$u k d$ North West (ENGLAND)

uke Yorkshire and The Humber

$u k f$ East Midlands (ENGLAND)

$u k g$ West Midlands (ENGLAND)

$u k h$ Eastern

$u k i$ London

ukj South East

$u k k$ South West (ENGLAND)

$u k l$ Wales

$u k m$ Scotland

$u k b$ Northern Ireland (UK)(NUTS95) 


\section{List of Eastern European countries}

(as used in the regressions)

Bulgaria

Czech Republic

Estonia

Hungary

Latvia

Lithunia

Poland

Romania

Slovenia

Slovakia

\section{List of South European countries}

(as used in the regressions)

Austria

Bulgaira

Cyprus

Spain

France

Greece

Hungary

Italy

Malta

Portugal

Romania 